Supporting Information for:

\title{
Using Adhesives to Capture Microplastics from Water
}

P. Takunda Chazovachii, ${ }^{a}$ Julie M. Rieland, ${ }^{b}$ Violet V. Sheffey, ${ }^{b}$ Timothy M. E. Jugovic, ${ }^{a}$ Paul M. Zimmerman, ${ }^{a}$ Omolola Eniola-Adefeso, ${ }^{d}$ Brian J. Love ${ }^{b, c}$ and Anne J. McNeila,b*

a. Department of Chemistry, University of Michigan, 930 North University Avenue, Ann Arbor, Michigan, 48109-1055, USA

b. Macromolecular Science and Engineering Program, University of Michigan, 2800 Plymouth Road, Ann Arbor, Michigan, 48109-2800, USA

c. Department of Materials Science and Engineering, University of Michigan, 2300 Hayward Street, Ann Arbor, Michigan, 48109-2117, USA

d. Department of Chemical Engineering, University of Michigan, 2300 Hayward Street, Ann Arbor, Michigan, 48109-2136, USA

\section{$\underline{\text { Table of Contents }}$}

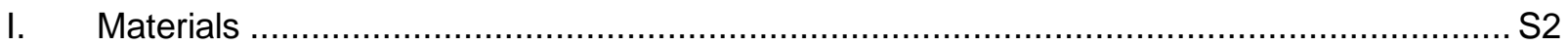

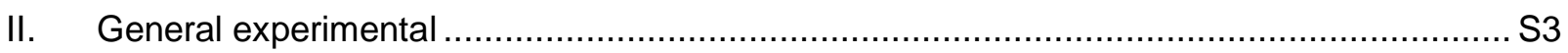

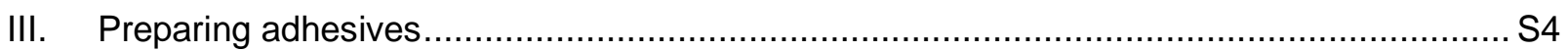

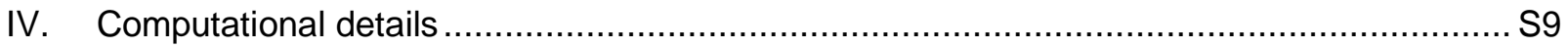

V. Evaluating microplastics removal efficiency ................................................................. S10

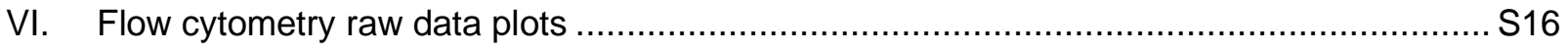

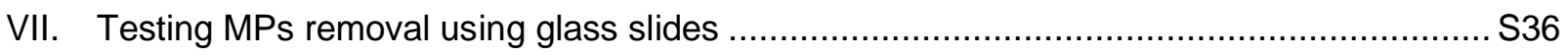

VIII. Testing MPs removal using glass slides with humic acid or surfactant present ...............S38

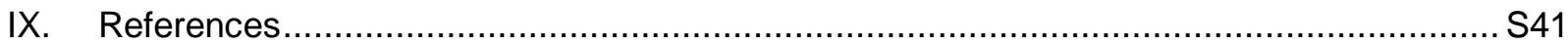




\section{Materials}

All chemicals were used as received unless otherwise mentioned. Polyacrylic acid (PAA) with molecular weight listed as $1,033 \mathrm{~kg} / \mathrm{mol}$ (PAAspP-1000k) was purchased from Scientific Polymer Products. Poly(2ethylhexyl acrylate) (P(2-EHA)) solution in toluene measured to be $93 \mathrm{~kg} / \mathrm{mol}(\mathrm{P}(2-\mathrm{EHA})$ sigma-93k), PAAsigma240k (listed as $240 \mathrm{~kg} / \mathrm{mol}$ and measured as $240 \mathrm{~kg} / \mathrm{mol}$ ), PAAsigma-370k (listed as $450 \mathrm{~kg} / \mathrm{mol}$ and measured as $370 \mathrm{~kg} / \mathrm{mol})$, 2-ethyl hexanol $(2-\mathrm{EHOH})$, sulfuric acid $\left(\mathrm{H}_{2} \mathrm{SO}_{4}\right)$, and sodium nitrate $\left(\mathrm{NaNO}_{3}\right)$ were purchased from Millipore Sigma. Methanol $(\mathrm{MeOH})$ and ethanol $(\mathrm{EtOH})$ were purchased from Fisher Scientific. Tetrahydrofuran (THF) was purchased from OmniSolv. Glacial acetic acid was purchased from Acros Organics. Deuterated solvents: chloroform $\left(\mathrm{CDCl}_{3}\right)$, pyridine- $d_{5}$, and deuterium oxide $\left(\mathrm{D}_{2} \mathrm{O}\right)$ were purchased from Cambridge Isotopes. Micronized rubber (MD-105-TR) was generously provided by Lehigh Technologies. The superabsorbent polymer (PAAP\&) was generously provided by Procter \& Gamble and is $70 \%$ neutralized (i.e., \% sodium form) and contains up to $1 \%$ by weight ethylene glycol diacrylate crosslinker relative to the acrylic acid monomer. Sonicated polymer fragments were dialyzed in deionized (DI) water using Spectra/Por molecular porous membrane tubing (molecular weight cut-off: $3.5 \mathrm{~kg} / \mathrm{mol}$ ). Pressure vessels were purchased from Thomas Scientific. Jacketed beakers were purchased from Sigma Aldrich (cat\#: Z202738-1EA). Zirconium silicate $\left(\mathrm{ZrSiO}_{4}\right)$ beads were purchased from Biospec Products, Inc. Ultrafiltered water was obtained from a Synergy Millipore Water Purification System. Nylon-12 powder (\#AM376010, avg size $\sim 30 \mu \mathrm{m}$ ) and PET powder (\#ES306031, max size $\sim 300 \mu \mathrm{m}$ ) were obtained from Goodfellow Cambridge Ltd. PE microspheres (\#CPMS-0.96 45-53 $\mu \mathrm{m}$, avg size $\sim 50 \mu \mathrm{m}$ ) were obtained from Cospheric. Rubber powder (ABR (All Black Rubber) 32-99 $\mu \mathrm{m}$ mesh material) was obtained from Entech. Humic acid (\#53680) was purchased from Aldrich and used without purification. Sodium dodecyl sulfate was purchased from Sigma Aldrich ( $\geq 98.5 \%$ purity). 


\section{General experimental}

NMR Spectroscopy - Unless otherwise noted, ${ }^{1} \mathrm{H}$ and ${ }^{13} \mathrm{C}$ NMR spectra for all compounds were acquired at room temperature. Chemical shift data are reported in units of $\delta(\mathrm{ppm})$ relative to tetramethylsilane (TMS) and referenced with residual solvent. Multiplicities are reported as follows: singlet (s), doublet (d), doublet of doublets (dd), triplet (t), quartet (q), multiplet $(\mathrm{m})$, and broad resonance (br). Residual water is denoted by an asterisk $\left({ }^{*}\right)$. For all ${ }^{1} \mathrm{H}$ NMR spectra of polymers, a $3.5 \mathrm{~s}$ acquisition time was used with a $10 \mathrm{~s}$ relaxation delay between each pulse.

SEC for pressure-sensitive adhesives (PSAs) - The synthesized PSAs were dissolved in THF (1 mg/mL) with mild heating and filtered through a PTFE filter $(0.45 \mu \mathrm{m})$ into an SEC vial. Polymer molar mass $(M)$ and dispersity $(\boxminus)$ were determined at $40{ }^{\circ} \mathrm{C}$ in THF on a SEC: Malvern Viscotek GPCMax VE2001 equipped with two Viscotek LT-5000L $8 \mathrm{~mm}$ (ID) $\times 300 \mathrm{~mm}$ (L) columns, and Viscotek TDA 305 and Viscotek RI detectors. Apparent molar masses were calculated using EasiVial PMMA standards (spanning $690-1,944,000 \mathrm{~g} / \mathrm{mol}$ ) provided by Polymer Laboratories.

Scanning electron microscope - Instrument- JEOL JSM-IT500HR with secondary electron (SE) imaging at $4 \mathrm{kV}$. No sputter coating was used. To prevent excessive charging, the beam was focused on an adjacent particle, then transferred to the point of interest, where a picture was taken in quick succession.

Optical microscopy - The glass slides were examined using a Leica DMCB optical microscope with a 5x/0.15 HC PL FLUOTAR objective lens and an external Fostec Ace 150W remote fiber optic light source with top illumination.

Flow cytometry - Flow cytometry was used to quantify the concentration of microplastics in aqueous suspensions. The technique is traditionally used to study physiochemical properties of cells (size, granularity, antibody expression, etc.) and sort different cellular populations according to their differences and/or similarities. Fluorescent staining is usually an integral part of the analysis because the complexity of cells necessitates it. In contrast, fluorescent staining was not necessary for this work as a single class of microplastics (10 $\mu \mathrm{m}$ polystyrene) was under inspection. The instrument used is an Attune NXT Flow Cytometer. The settings are as follows: forward scatter detector gain $(200 \mathrm{mV})$, sample flow rate $(25$ $\mu \mathrm{L} / \mathrm{min})$, and sample volume $(30 \mu \mathrm{L})$. 


\section{Preparing adhesives}

\section{A. P(2-EHA)sigma-93k}

A commercial solution of $\mathrm{P}(2-\mathrm{EHA})$ sigma-93k in toluene $(20 \mathrm{~mL})$ was purified by precipitating into $\mathrm{MeOH}(30$ $\mathrm{mL}$ ) once and washing with $\mathrm{MeOH} 3$ times. Centrifugation was used to separate the polymer from the supernatant. The polymer was dried under high vacuum at $60^{\circ} \mathrm{C}$ for $3 \mathrm{~h}$.

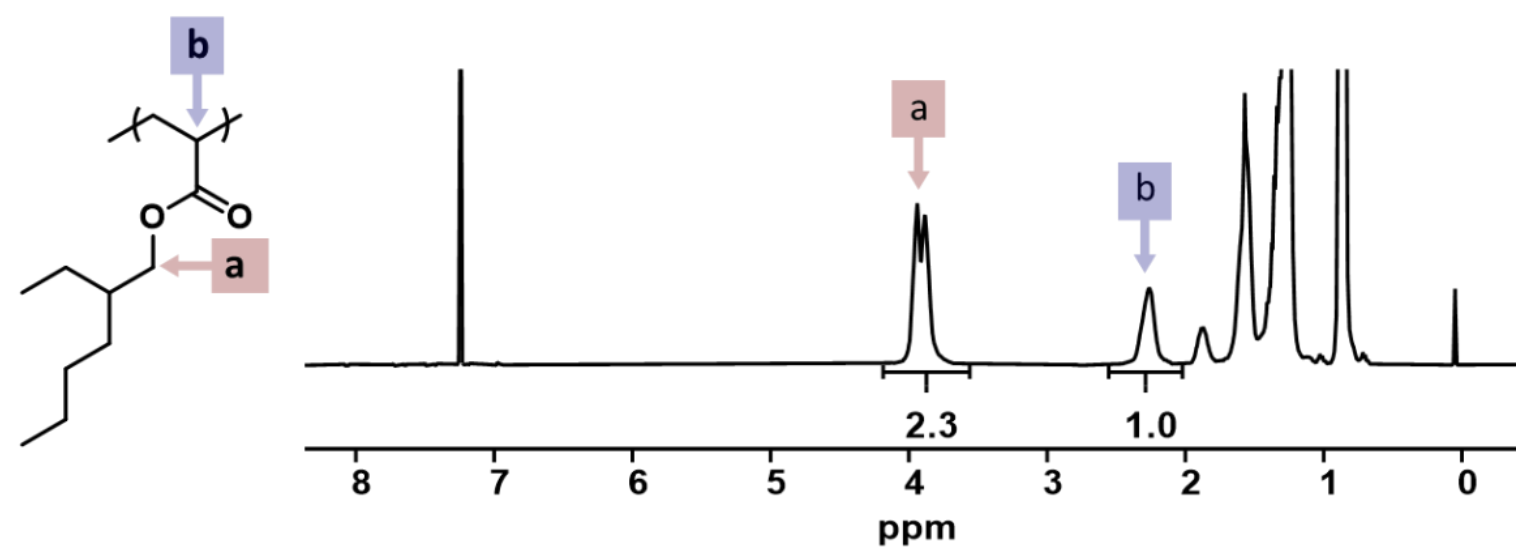

Figure S1. $\quad{ }^{1} \mathrm{H}$ NMR spectra of $\mathrm{P}(2-\mathrm{EHA})_{\text {Sigma-93k }}\left(500 \mathrm{MHz}, \mathrm{CDCl}_{3}\right)$. 


\section{B. P(2-EHA)sigma-370k and P(2-EHA)sPP-950k}

\section{Chain-Shortening PAASPP-1000k}

PAAsPP-1000k $(2,500 \mathrm{mg}, 34.7 \mathrm{mmol})$ and DI water $(50 \mathrm{~mL})$ was added to a jacketed beaker $(3.5 \mathrm{~cm}$ inner diameter, $9 \mathrm{~cm}$ height) equipped with a stir bar and left to stir (500 rpm) for $12 \mathrm{~h}$. Then, cold water (10-15 ${ }^{\circ} \mathrm{C}$ ) was flowed through the jacket. The contents were sonicated for $5 \mathrm{~min}$ at $100 \%$ amplitude ( $300 \mathrm{~W}$ based on a kill-a-watt device) using a Sonics and Materials Vibra-cell VCX 600 Ultrasonic Liquid Processor equipped with a $13 \mathrm{~mm}$ replaceable tip probe. A thermocouple was immersed into the polymer solution to monitor temperature, which rose from 15 to $60^{\circ} \mathrm{C}$.

After sonication, the polymer was dialyzed using DI water ( 1 gallon), switching the DI water three times over 12-18 $\mathrm{h}$. Then, the polymer was freeze-dried and ground to a fine powder using a mortar and pestle. More specifically, while wearing cryogenic gloves, a piece of freeze-dried polymer was put into a mortar, which was then immersed into a bath of liquid $\mathrm{N}_{2}$. A small amount of liquid $\mathrm{N}_{2}$ was poured into the mortar and the polymer was ground using a pestle. The fine powder was immediately transferred to a $20 \mathrm{~mL}$ vial and held under high vacuum for $10 \mathrm{~min}$ as the polymer warmed to rt to avoid water condensation.

\section{Esterifying PAAsPP-1000k and PAAsigma-240k}

Note that PAAsigma-240k was used for esterification without chain-shortening.

2-EHOH (16.27 mL, $104.1 \mathrm{mmol}, 5.00$ equiv), $\mathrm{H}_{2} \mathrm{SO}_{4}(0.277 \mathrm{~mL}, 5.20 \mathrm{mmol}, 0.25$ equiv), and chainshortened PAAsP-1000k or PAAsigma-240k $(1,500 \mathrm{mg}, 20.8 \mathrm{mmol}, 1.00$ equiv) were added to a $75 \mathrm{~mL}$ pressure vessel, along with a stir bar. The vessels were sealed with a Teflon screw cap and heated to $120^{\circ} \mathrm{C}$ for 8 h. Thereafter, the vessel was cooled to rt in a water bath. Next, the reaction mixture was poured into $\mathrm{MeOH}$ $(\sim 50 \mathrm{~mL})$ to precipitate the $\mathrm{P}(2-\mathrm{EHA})$. The resulting $\mathrm{P}(2-\mathrm{EHA})$ spp-950k or $\mathrm{P}(2-\mathrm{EHA})_{\text {sigma-370k obtained was }}$ purified by dissolving in minimal amounts of THF $(\sim 10 \mathrm{~mL})$ and precipitating with $\mathrm{MeOH}(\sim 50 \mathrm{~mL})$. The polymer was isolated by centrifugation and decanting off the supernatant. This precipitation process was repeated three times. Aft the final isolation, the polymer was dried under high vacuum with heating at 60 ${ }^{\circ} \mathrm{C}$ for $3 \mathrm{~h}$. The isolated yield was $73 \% \mathrm{P}(2-\mathrm{EHA})_{\text {SPP-950k }}$ and $82 \%$ for $\mathrm{P}(2-\mathrm{EHA})_{\text {sigma-370k. }}$

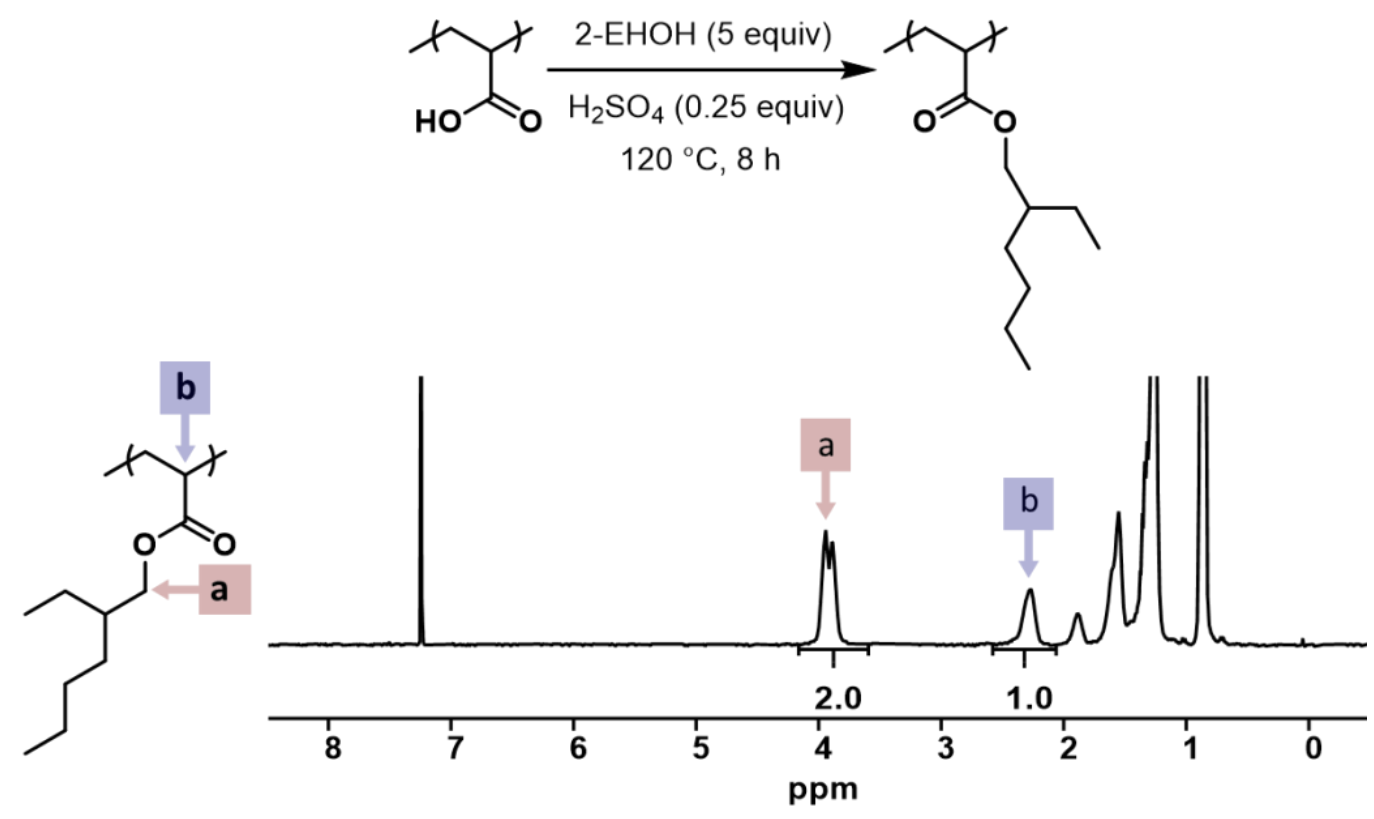

Figure S2. ${ }^{1} \mathrm{H}$ NMR spectra of $\mathrm{P}(2-\mathrm{EHA})$ SPP-950k $\left(500 \mathrm{MHz}, \mathrm{CDCl}_{3}\right)$. 


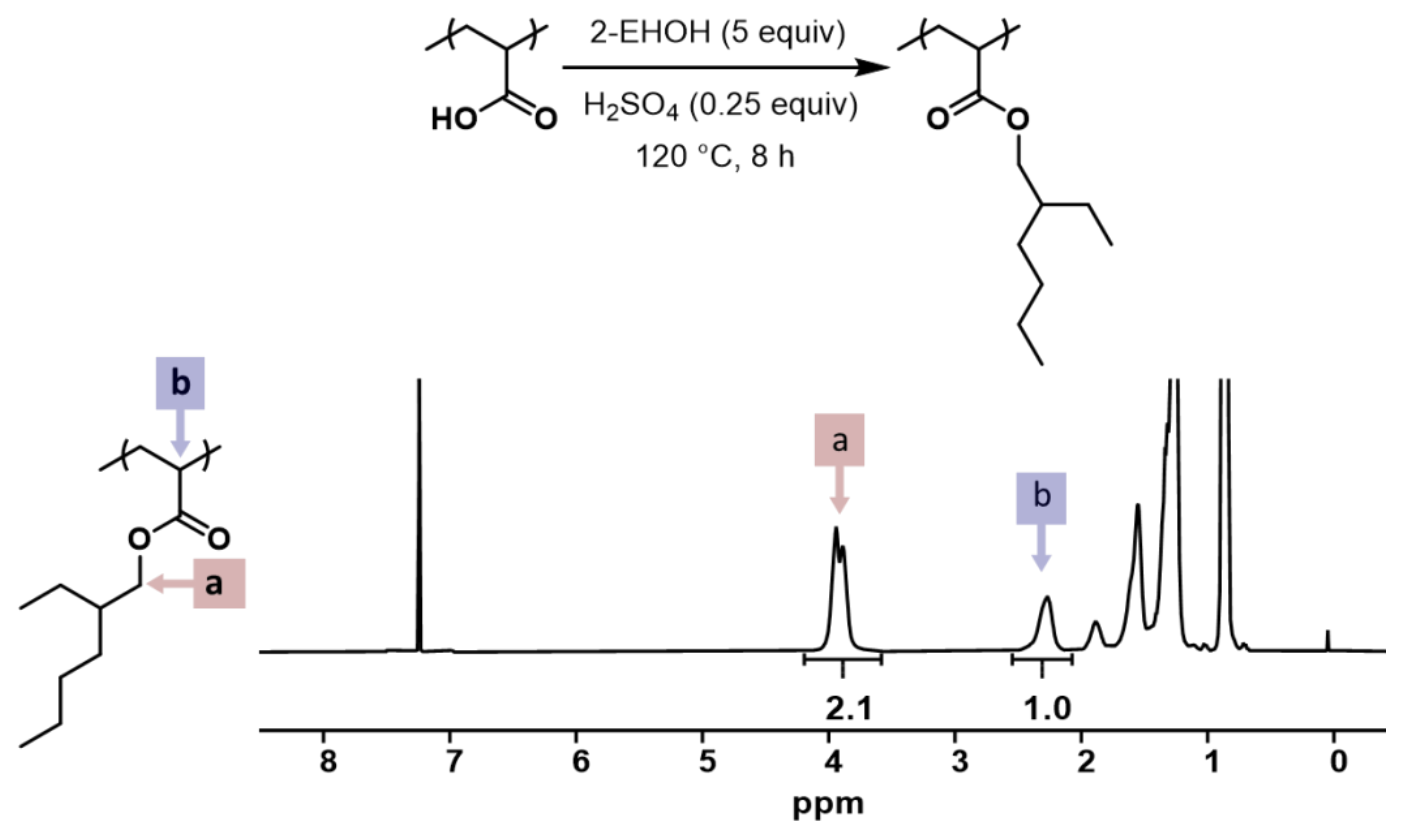

Figure S3. ${ }^{1} \mathrm{H}$ NMR spectra of $\mathrm{P}(2-\mathrm{EHA})_{\text {Sigma-370k }}\left(500 \mathrm{MHz}, \mathrm{CDCl}_{3}\right)$. 


\section{P(2-EHA)P\&G-590k}

(i) Decrosslinking: A $0.8 \mathrm{M}$ aq. $\mathrm{H}_{2} \mathrm{SO}_{4}$ solution was prepared by adding $\mathrm{H}_{2} \mathrm{SO}_{4}(6.84 \mathrm{~mL}, 128 \mathrm{mmol}, 1.5$ equiv) to a $350 \mathrm{~mL}$ pressure vessel containing $\mathrm{DI} \mathrm{H} \mathrm{H}_{2} \mathrm{O}(160 \mathrm{~mL})$ stirring at $350 \mathrm{rpm}$. Thereafter, PAAP\& $\left(8,000 \mathrm{mg}, 85.1 \mathrm{mmol}, 1\right.$ equiv) was added. The vessel was sealed, and the reaction stirred at $120^{\circ} \mathrm{C}$ for $24 \mathrm{~h}$. The resulting reaction mixture was used directly in the subsequent sonication experiments.

(ii) Chain-shortening: Decrosslinked PAAP\&G solution $(\sim 50 \mathrm{~mL})$ was poured into a jacketed beaker $(3.5 \mathrm{~cm}$ inner diameter, $9 \mathrm{~cm}$ height) equipped with a stir bar. While flowing cold water $\left(10-15^{\circ} \mathrm{C}\right)$ through the jacket, the decrosslinked PAAP\&G was sonicated for $5 \mathrm{~min}$ at $100 \%$ amplitude (290 W based on a kill-a-watt device) using a Sonics and Materials Vibra-cell VCX 600 Ultrasonic Liquid Processor equipped with a 13 $\mathrm{mm}$ replaceable tip probe. A thermocouple was immersed into the polymer solution to monitor temperature, which rose from $23^{\circ} \mathrm{C}$ to $45^{\circ} \mathrm{C}$.

After sonication, the polymer was dialyzed using DI water ( 1 gallon), switching the DI water three times over 12-18 $\mathrm{h}$. Then, the polymer was freeze-dried and ground to a fine powder using a mortar and pestle. More specifically, while wearing cryogenic gloves, a piece of freeze-dried polymer was put into a mortar, which was then immersed into a bath of liquid $\mathrm{N}_{2}$. A small amount of liquid $\mathrm{N}_{2}$ was poured into the mortar and the polymer was ground using a pestle. The fine powder was immediately transferred to a $20 \mathrm{~mL}$ vial and held under high vacuum for $10 \mathrm{~min}$ as the polymer warmed to rt to avoid water condensation. The polymer was isolated in $91 \%$ yield (over both steps).

(iii) Esterification: To a $75 \mathrm{~mL}$ pressure vessel, 2-EHOH $\left(4.34 \mathrm{~mL}, 27.8 \mathrm{mmol}, 5.00\right.$ equiv.) and $\mathrm{H}_{2} \mathrm{SO}_{4}$ ( $0.074 \mathrm{~mL}, 1.39 \mathrm{mmol}, 0.25$ equiv.) were added and stirred at $120^{\circ} \mathrm{C}$. While stirring, chain-shortened PAAP\& (400 mg, $5.60 \mathrm{mmol}, 1.00$ equiv.) was subsequently added and the vessel was sealed with a Teflon screw cap and stirred for $10 \mathrm{~h}$ at $120^{\circ} \mathrm{C}$. Thereafter, the vessel was cooled in a rt water bath. The $\mathrm{P}(2-$ EHA)P\&G-590k was isolated by precipitating into $\mathrm{MeOH}(20 \mathrm{~mL})$ and removing the supernatant. Then, the polymer was purified by dissolving in minimal amounts of THF $(5 \mathrm{~mL})$, precipitating into $\mathrm{MeOH}(20 \mathrm{~mL})$, and removing the supernatant after centrifugation. This process was repeated three times. The resulting solid was dried under high vacuum at $80^{\circ} \mathrm{C}$ for $10 \mathrm{~h}$. The isolated yield was $79 \%$.

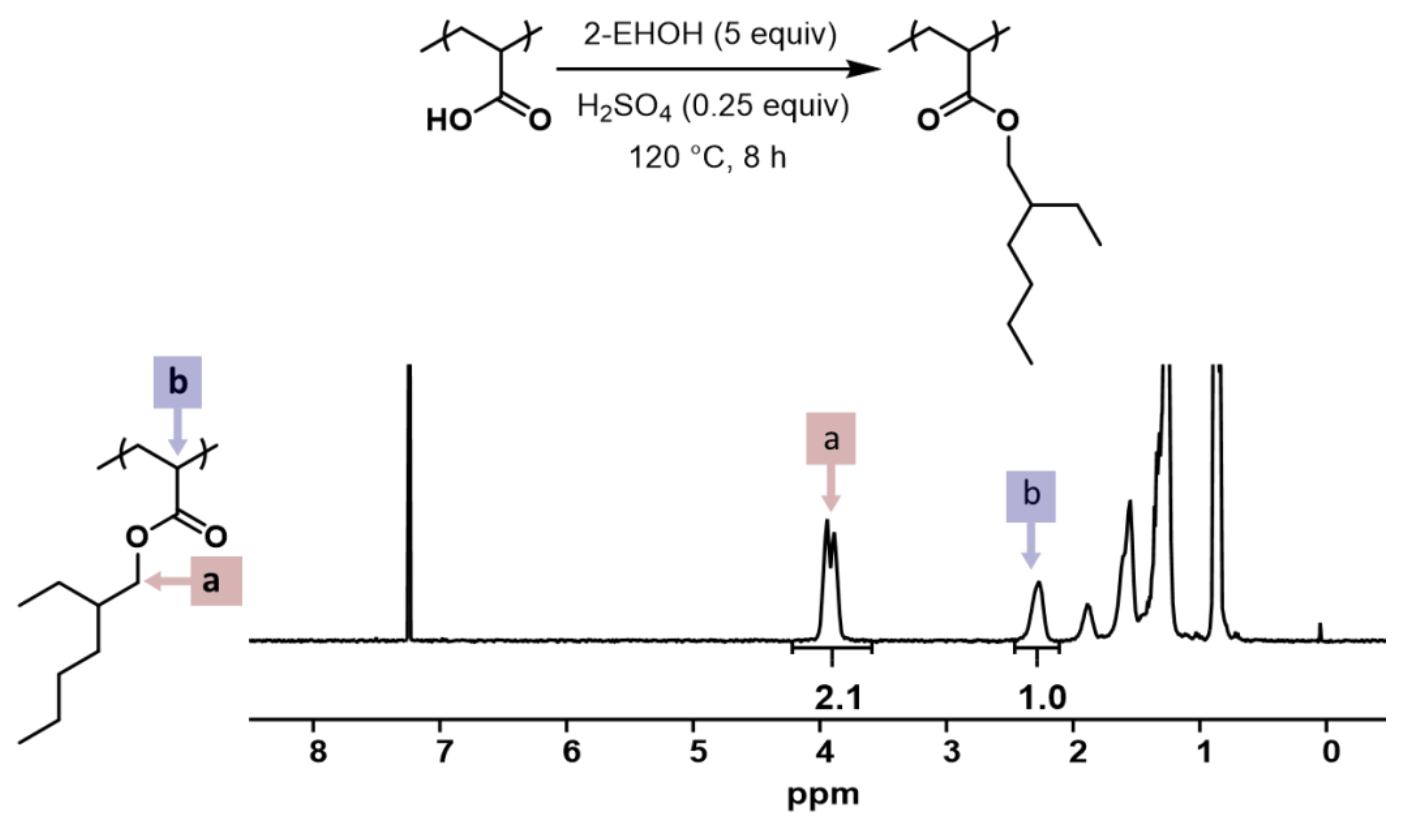

Figure S4. ${ }^{1} \mathrm{H}$ NMR spectra of $\mathrm{P}(2-\mathrm{EHA})$ P\&G-590k $\left(500 \mathrm{MHz}, \mathrm{CDCl}_{3}\right)$. 

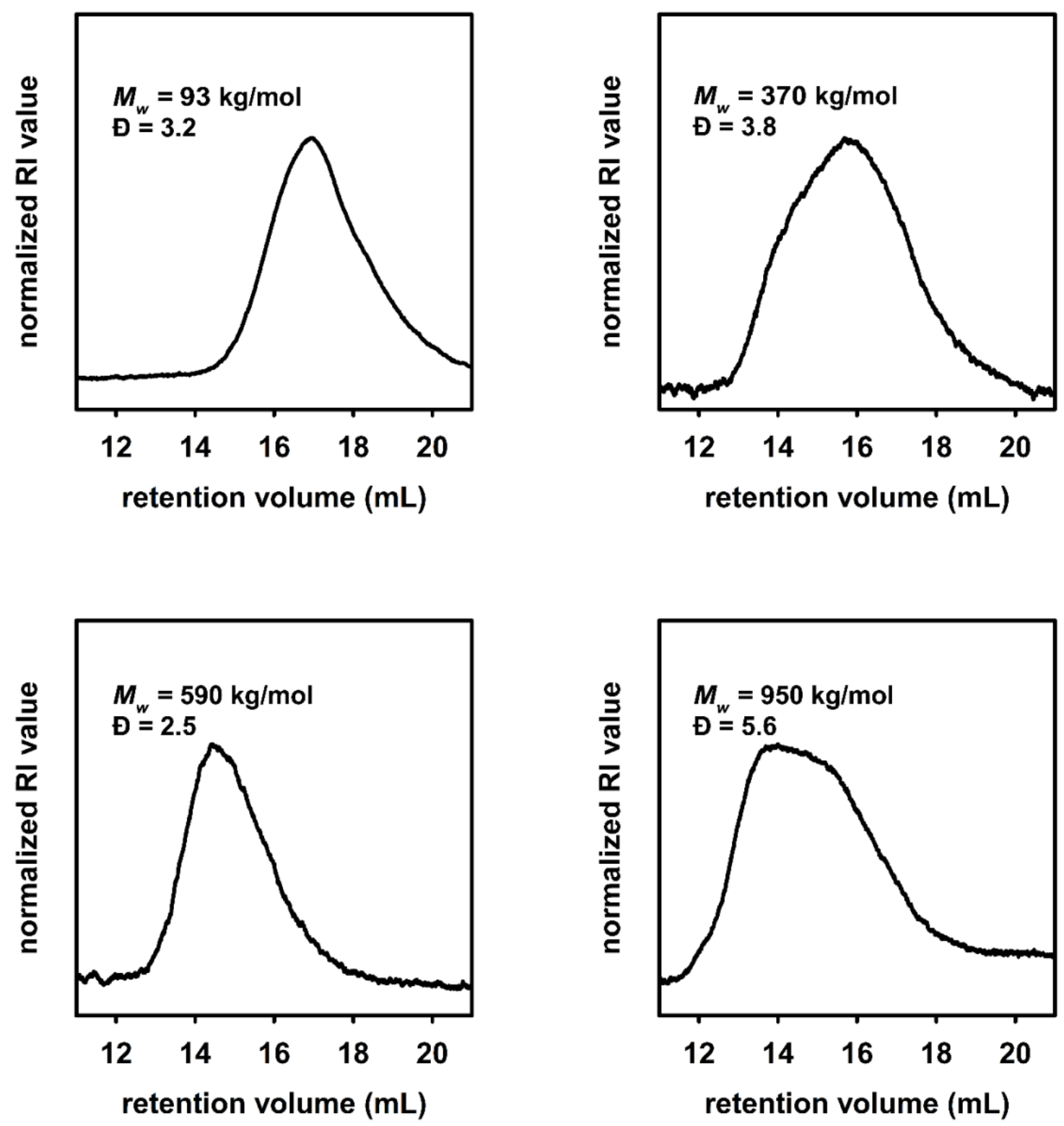

Figure S5. Size-exclusion chromatography traces of the synthesized $\mathrm{P}(2-\mathrm{EHA}) \mathrm{s}$ where $M_{w}$ refers to the weight-average molar mass and $\boxminus$ refers to the dispersity. 


\section{Computational details}

\section{Methods and molecular dynamics sampling}

Molecular dynamic simulations were conducted using the cgenff molecular mechanics forcefield and the GPU-enabled c45a2 version of CHARMM package. Initial structures for microplastic surfaces were generated using the CHARMM-GUI. Initial structures for adhesives were generated by an in-house python code algorithm which produces CHARMM ready input structures of R-group modified polyacrylate adhesives from monomer geometries. The algorithm works by taking CHARMM optimized polyacrylate monomer geometries and generating a linear sequence of bonded residues, analogous to unrelaxed protein strands. Both types of structures were then equilibrated at $298.15 \mathrm{~K}$ under NVT conditions for $10 \mathrm{~ns}$. The Packmol program ${ }^{2}$ was used to create adhesive-water and adhesive-plastic interfaces, starting from the pre-equilibrated initial structures. Adhesive-water systems were equilibrated at $298.15 \mathrm{~K}$ under NPT conditions for 50 ns before production runs for 10 ns with NVT conditions with frame sampling every 50 ps. Adhesive-plastic systems were equilibrated at $298.15 \mathrm{~K}$ under NVT conditions for 50 ns before productions runs under the same conditions for $10 \mathrm{~ns}$ with frame sampling every $50 \mathrm{ps}$. Interfacial surface tension was calculated with the Lee-Richards method to determine interfacial surface area and energies. ${ }^{3}$ Each simulation provided 200 frames with interfacial surface tension analysis, from which the mean was taken for the value and standard deviation for error bars.

\section{Adhesive models and statistical sampling}

As 2-EHA is a chiral monomer, statistical sampling of the polymer structure was used to prevent unintentional clustering of monomeric chirality in residue sequences which would cause outlier results. As such, the adhesive construction algorithm was used to independently construct three P(2-EHA) adhesive chains, of approximately the same molecular weight, which were then relaxed to their equilibrium state. Each of these three adhesives was then simulated with the aqueous and plastic surfaces 10 separate times to produce 30 total simulations of 200 frames each. Simulation $\gamma$ values were averaged, and errors combined with any outliers removed based on Dixon's Q-test method. ${ }^{4}$ Final $\gamma$ and work of adhesion value are reported in SI TABLE S1 below.

Table S1. Computed $\gamma$ values and work of adhesion values for plastics with $\mathrm{P}(2-\mathrm{EHA})$.

\begin{tabular}{|l|l|l|l|}
\hline plastic material & $\gamma_{\text {adhesive-water }}(\mathbf{m N} / \mathbf{m})^{\ddagger}$ & $\gamma_{\text {adhesive-plastic }}(\mathbf{m N} / \mathbf{m})$ & $\begin{array}{l}W_{0 A} \\
(\mathbf{m N} / \mathbf{m})\end{array}$ \\
\hline Polyethylene terephthalate & $-49.19 \pm 0.27$ & $-27.97 \pm 0.20$ & $21.22 \pm 0.34$ \\
\hline Polystyrene & $-49.19 \pm 0.27$ & $-19.31 \pm 1.30$ & $29.87 \pm 1.32$ \\
\hline Polyethylene & $-49.19 \pm 0.27$ & $-18.75 \pm 1.09$ & $30.44 \pm 1.12$ \\
\hline Nylon-6 & $-49.19 \pm 0.27$ & $-24.52 \pm 1.05$ & $24.67 \pm 1.08$ \\
\hline
\end{tabular}

$\ddagger$ This value is constant for a given adhesive composition and size. 


\section{Evaluating microplastics removal efficiency}

\section{A. Coating the beads}

Four types of adhesive coated beads (P(2-EHA)spP-950k, $\mathrm{P}(2-\mathrm{EHA})$ sigma-370k, $\mathrm{P}(2-\mathrm{EHA}) \mathrm{P} \& \mathrm{G}-590 \mathrm{k}$, and $\mathrm{P}(2-$ EHA)sigma-93k) were prepared independently. $\mathrm{ZrSiO}_{4}$ beads $(0.5 \mathrm{~mm}, 20.0 \mathrm{~g})$ were added to a $20 \mathrm{~mL}$ vial and washed by adding acetone $(10 \mathrm{~mL})$ and shaking for $30 \mathrm{~s}$. Then, the solvent was removed using a needle and syringe. The beads were spread onto aluminum foil and oven dried $\left(120^{\circ} \mathrm{C}\right)$ for $10 \mathrm{~min}$. After cooling to ambient temperature, adhesive solution in THF, $(1.0 \mathrm{~mL}, 5 \% \mathrm{w} / \mathrm{v}$.) was added and the beads were handshaken ( 3 shakes per second) for 2 min. The solvent was removed by drying under high vacuum for $3 \mathrm{~h}$.

\section{B1. Surface charge measurements}

Approximately $2 \mathrm{mg}$ of $10 \mu \mathrm{m}$ PS microplastics were dispersed in $1 \mathrm{~mL}$ of DI water. The dispersion was mixed for $30 \mathrm{~s}$ on a vortex spinner then sonicated for $30 \mathrm{~s}$ to ensure an even suspension. The suspension was then transferred to a DTS1060 disposable capillary cell. The zeta potential was measured at ambient temperature $\left(22^{\circ} \mathrm{C}\right)$ on a Malvern Zetasizer Nano and calculated using the Smoluchowski model. The data was acquired with no delay times to ensure measurement before floating and aggregation of particles occurred. There was a progressive decrease in $\zeta$ potential observed over a period of $20 \mathrm{~min}$, which suggests some degree of charge loss to the water. Overall, the $10 \mu \mathrm{m}$ PS particles maintain a slightly negative charge in all samples.

Table S2. Mean Zeta potential data with standard deviation

\begin{tabular}{|c|c|}
\hline run \# & $\begin{array}{c}\text { mean } \zeta \text { potential with } \\
\text { standard deviation }(\mathrm{mV})\end{array}$ \\
\hline 1 & $-22.0 \pm 6.3$ \\
2 & $-22.0 \pm 10.6$ \\
3 & $-15.8 \pm 8.2$ \\
4 & $-17.6 \pm 4.8$ \\
5 & $-13.2 \pm 6.1$ \\
6 & $-12.9 \pm 6.2$ \\
\hline
\end{tabular}

\section{B2. Preparing microplastics suspension}

Two stock suspensions of PS $(1.0 \mathrm{mg} / \mathrm{mL})$ in $80 / 20 \mathrm{H}_{2} \mathrm{O} / \mathrm{EtOH}$ were prepared by adding PS (40.1 mg, 10 $\mu \mathrm{m})$, nano pure $\mathrm{H}_{2} \mathrm{O}(32.0 \mathrm{~mL})$, and $\mathrm{EtOH}(8.00 \mathrm{~mL})$ to $50 \mathrm{~mL}$ centrifuge tubes. The mixture was vortex mixed at 10 setting for $30 \mathrm{~s}$ and sonicated for $15 \mathrm{~min}$.

\section{Microplastics removal}

Four time points $(0.5,1,3$, and $5 \mathrm{~min})$ and four replications for each time point (i.e., each time point was run $4 \mathrm{x}$ ) were collected (i.e., 64 samples) for each of the four adhesives. To accomplish this goal, adhesivecoated beads ( $400 \mathrm{mg}$ ) were added to sixty-four $4 \mathrm{~mL}$ vials, which were labeled accordingly.

The stock PS suspension $(40.0 \mathrm{~mL}, 1.0 \mathrm{mg} / \mathrm{mL})$ was hand-shaken to homogenize followed by transferring $1.00 \mathrm{~mL}$ using a needle (18 gauge) and syringe $(1 \mathrm{~mL}$ ) into the $4 \mathrm{~mL}$ vials containing the adhesive-coated beads. Immediately after transferring the suspension, the vials were hand-shaken (approx. 3 shakes per $\mathrm{s}$ ) for the appropriate time $(0.5,1,3$, and $5 \mathrm{~min})$. After shaking, a needle (18 gauge) and syringe ( $3 \mathrm{~mL})$ was used to transfer the remaining microplastic suspensions into a $1.5 \mathrm{~mL}$ Eppendorf tubes and stored in the refrigerator until quantification via flow cytometry was performed (within $2 \mathrm{~d}$ ).

Note: For each time point, Julie Rieland performed the handshaking on replicates number 2 and 3 while Takunda Chazovachii did the hand-shaking on replicates number 1 and 4. 


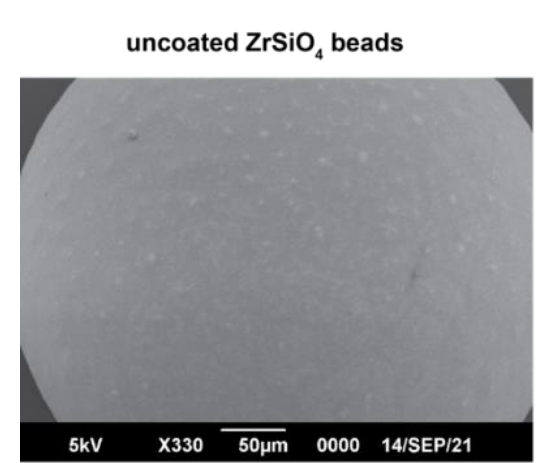

beads coated with $\mathrm{P}(2-\mathrm{EHA})_{93 \mathrm{k}}$ at $5 \mathrm{w} / \mathrm{v} \%$ beads coated with $\mathrm{P}(2-\mathrm{EHA})_{93 \mathrm{k}}$ at 10 and $20 \mathrm{w} / \mathrm{v} \%$ ( $1 \mathrm{~mL}$ for $20 \mathrm{~g}$ of beads) ( $1 \mathrm{~mL}$ for $0.5 \mathrm{~g}$ of beads)
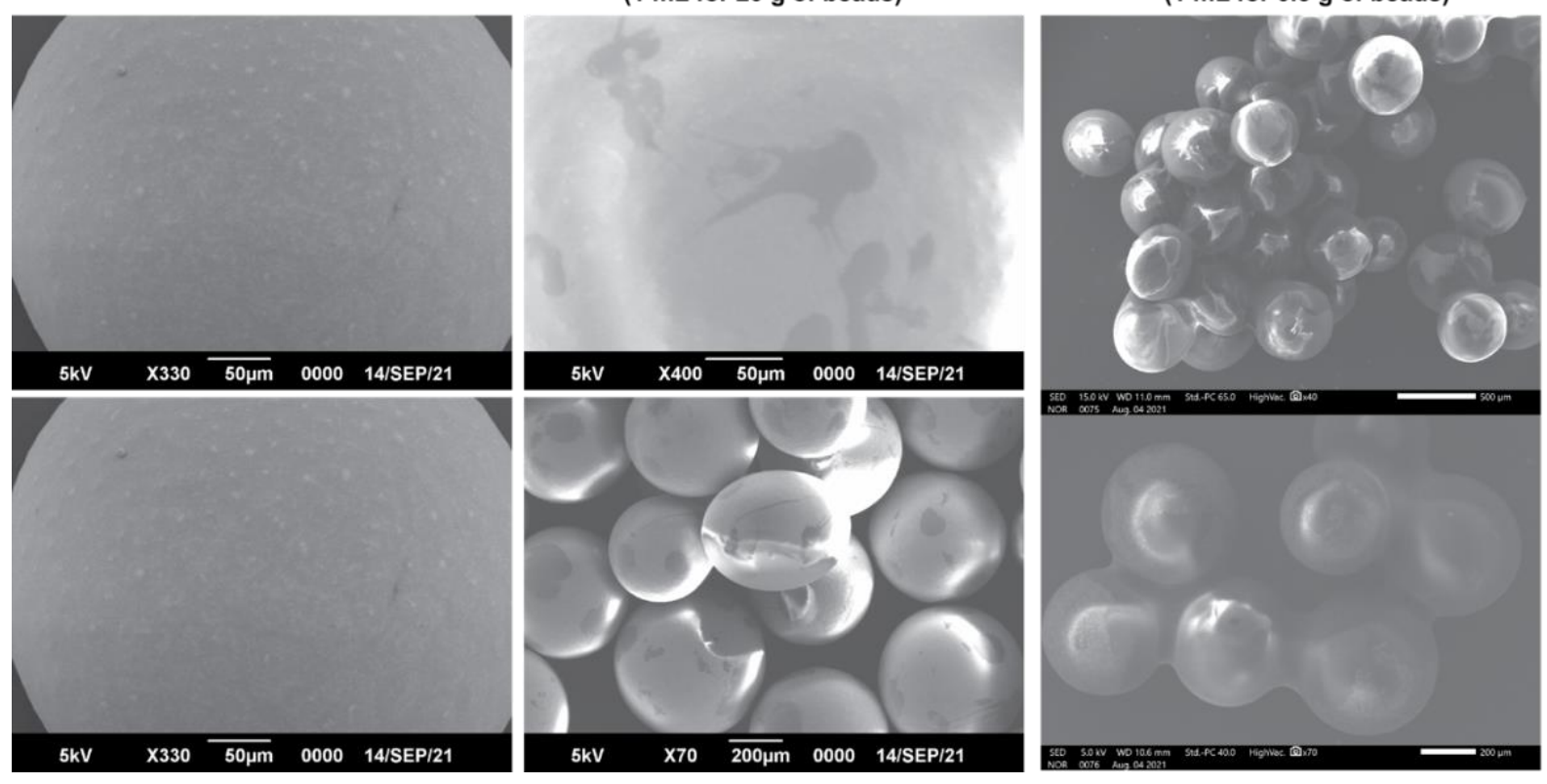

Figure S6. SEM images of uncoated $\mathrm{ZrSiO}_{4}$ beads (left), beads coated with $\mathrm{P}(2-\mathrm{EHA})_{93 \mathrm{k}}$ according to the general procedure (middle), and beads coated with $\mathrm{P}(2-\mathrm{EHA})_{93 k}$ at higher concentration of adhesive relative to beads (right). 


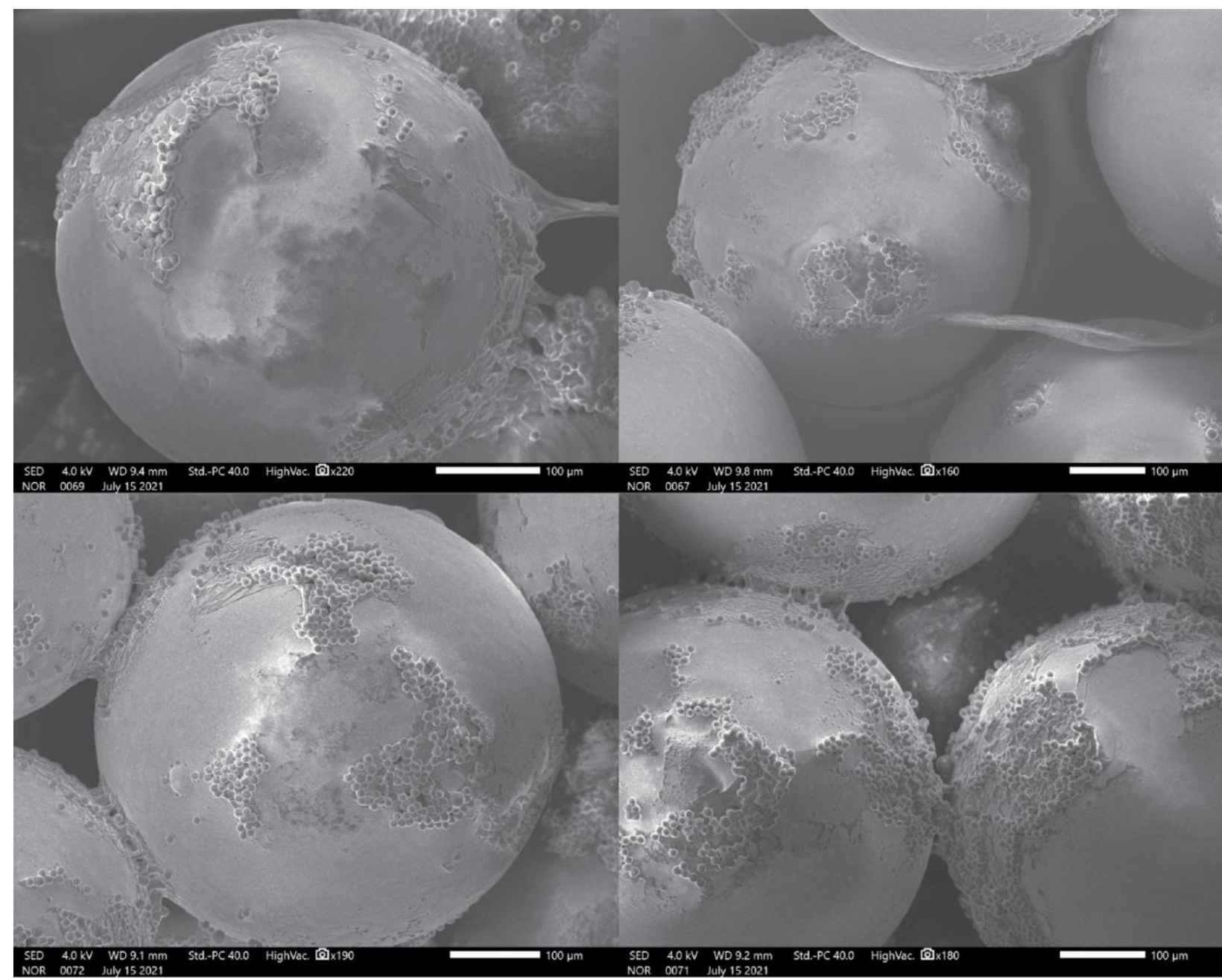

Figure S7. Additional SEM images of $\mathrm{P}(2-\mathrm{EHA})_{590 k}$-coated beads after a 5 min exposure to the PS microplastic solution.

\section{Flow cytometry analysis}

Residual microplastics concentrations post capture was quantified using an Attune NxT Acoustic Focusing Cytometer (Thermo Fisher Scientific) with the following instrument settings: forward scatter (FSC) detector voltage $(200 \mathrm{mV})$, sample flow rate $(25 \mu \mathrm{L} / \mathrm{min})$, and sample volume $(30 \mu \mathrm{L})$. Prior to injection in the instrument, all samples were briefly vortexed. Data analysis was performed on FlowJo software (Tree Star). Singlets, doublets, and triplet populations were determined according to the magnitude of the FSC area, and the final microplastics concentration $(C)$ in particles $/ \mathrm{mL}$ was calculated using the following equation, where $E_{1}, E_{2}$ and $E_{3}$ represent singlet, doublet and triplet event counts, respectively:

$$
C=\frac{1000\left(E_{1}+2 E_{2}+3 E_{3}\right)}{30}
$$


Table S3. Processed data from the flow cytometry experiments plotted in Figures S8-S24. Note that the raw data was first multiplied by a factor of 33.3 to convert the $30 \mu \mathrm{L}$ injection volume to a count $/ \mathrm{mL}$ for this table.

\begin{tabular}{|c|c|c|c|c|c|c|}
\hline sample information & singlets/mL & doublets/mL & triplets $/ \mathrm{mL}$ & other/mL $\mathbf{m}^{\mathrm{a}}$ & sum/mL & $\begin{array}{l}\% \\
\text { removal }\end{array}$ \\
\hline PS stock 1 & 923774.28 & 225707.4 & 25474.5 & 5766.09 & 1174956.18 & 0 \\
\hline PS stock 2 & 908309.16 & 233566.2 & 28571.4 & 5799.42 & 1170446.76 & 0 \\
\hline PS stock 3 & 781955.13 & 286380 & 42557.4 & 5832.75 & 1110892.53 & 0 \\
\hline PS stock 4 & 673999.26 & 357642 & 93006.9 & 7665.9 & 1124648.16 & 0 \\
\hline PS stock 5 & 674065.92 & 345853.8 & 79420.5 & 7765.89 & 1099340.22 & 0 \\
\hline Sigma-93k 5min 1 & 5866.08 & 1065.6 & 399.6 & 28597.14 & 7331.28 & 99.4 \\
\hline Sigma-93k 5min 2 & 10998.9 & 3196.8 & 999 & 17798.22 & 15194.7 & 98.7 \\
\hline Sigma-93k 5min 3 & 14798.52 & 3130.2 & 799.2 & 13631.97 & 18727.92 & 98.4 \\
\hline Sigma-93k 5min 4 & 12665.4 & 4129.2 & 1098.9 & 18998.1 & 17893.5 & 98.4 \\
\hline Sigma-93k 3min 1 & 29697.03 & 12387.6 & 5994 & 20764.59 & 48078.63 & 95.8 \\
\hline Sigma-93k 3min 2 & 30430.29 & 6460.2 & 2297.7 & 13431.99 & 39188.19 & 96.6 \\
\hline Sigma-93k 3min 3 & 33230.01 & 11122.2 & 4095.9 & 16898.31 & 48448.11 & 95.7 \\
\hline Sigma-93k 3min 4 & 25530.78 & 11322 & 3396.6 & 21164.55 & 40249.38 & 96.5 \\
\hline Sigma-93k $1 \min 1$ & 101589.84 & 33433.2 & 18481.5 & 34229.91 & 153504.54 & 86.5 \\
\hline Sigma-93k $1 \min 2$ & 101389.86 & 35697.6 & 16683.3 & 13198.68 & 153770.76 & 86.5 \\
\hline Sigma-93k $1 \mathrm{~min} 3$ & 110155.65 & 46153.8 & 35164.8 & 9732.36 & 191474.25 & 83.1 \\
\hline Sigma-93k $1 \mathrm{~min} 4$ & 75525.78 & 30769.2 & 18081.9 & 21797.82 & 124376.88 & 89.1 \\
\hline Sigma-93k 0.5min 1 & 110855.58 & 41292 & 19780.2 & 34629.87 & 171927.78 & 84.9 \\
\hline Sigma-93k 0.5min 2 & 130786.92 & 51415.2 & 35364.6 & 10598.94 & 217566.72 & 80.8 \\
\hline Sigma-93k 0.5min 3 & 179582.04 & 68464.8 & 42357.6 & 12765.39 & 290404.44 & 74.4 \\
\hline Sigma-93k 0.5min 4 & 133153.35 & 43223.4 & 21078.9 & 20897.91 & 197455.65 & 82.6 \\
\hline P\&G-590k 5min 1 & 12865.38 & 865.8 & 199.8 & 2299.77 & 13930.98 & 98.8 \\
\hline P\&G-590k 5min 2 & 11498.85 & 1332 & 99.9 & 2766.39 & 12930.75 & 98.9 \\
\hline P\&G-590k 5min 3 & 19598.04 & 1864.8 & 399.6 & 1866.48 & 21862.44 & 98.1 \\
\hline P\&G-590k 5min 4 & 13865.28 & 1598.4 & 199.8 & 3033.03 & 15663.48 & 98.6 \\
\hline P\&G-590k 3min 1 & 40995.9 & 8058.6 & 899.1 & 2666.4 & 49953.6 & 95.6 \\
\hline P\&G-590k 3min 2 & 98790.12 & 15651 & 2397.6 & 2899.71 & 116838.72 & 89.7 \\
\hline P\&G-590k 3min 3 & 64260.24 & 9390.6 & 1198.8 & 1933.14 & 74849.64 & 93.4 \\
\hline P\&G-590k 3min 4 & 48928.44 & 8325 & 999 & 1533.18 & 58252.44 & 94.9 \\
\hline P\&G-590k $1 \mathrm{~min} 1$ & 187381.26 & 41625 & 7992 & 2066.46 & 236998.26 & 79.1 \\
\hline P\&G-590k $1 \mathrm{~min} 2$ & 250441.62 & 74791.8 & 11188.8 & 2833.05 & 336422.22 & 70.4 \\
\hline P\&G-590k $1 \mathrm{~min} 3$ & 192980.7 & 52081.2 & 7392.6 & 2366.43 & 252454.5 & 77.8 \\
\hline P\&G-590k $1 \mathrm{~min} 4$ & 171516.18 & 25108.2 & 2997 & 2766.39 & 199621.38 & 82.4 \\
\hline P\&G-590k 0.5min 1 & 271039.56 & 72460.8 & 13486.5 & 3866.28 & 356986.86 & 68.6 \\
\hline P\&G-590k 0.5min 2 & 391627.5 & 92574 & 11988 & 1866.48 & 496189.5 & 56.3 \\
\hline P\&G-590k 0.5min 3 & 421524.51 & 139393.8 & 24175.8 & 2966.37 & 585094.11 & 48.5 \\
\hline P\&G-590k 0.5min 4 & 315601.77 & 76257 & 18481.5 & 2799.72 & 410340.27 & 63.9 \\
\hline Sigma-370k 5 min 1 & 48295.17 & 11655 & 2797.2 & 2666.4 & 62747.37 & 94.5 \\
\hline Sigma-370k $5 \mathrm{~min} 2$ & 66893.31 & 18381.6 & 3296.7 & 2499.75 & 88571.61 & 92.2 \\
\hline Sigma-370k $5 \mathrm{~min} 3$ & 88457.82 & 32434.2 & 11688.3 & 2066.46 & 132580.32 & 88.3 \\
\hline Sigma-370k $5 \mathrm{~min} 4$ & 47961.87 & 14718.6 & 2497.5 & 3266.34 & 65177.97 & 94.3 \\
\hline
\end{tabular}




\begin{tabular}{|c|c|c|c|c|c|c|}
\hline Sigma-370k $3 \min 1$ & 89891.01 & 39094.2 & 16183.8 & 2666.4 & 145169.01 & 87.2 \\
\hline Sigma-370k $3 \min 2$ & 189581.04 & 60939 & 16583.4 & 2966.37 & 267103.44 & 76.5 \\
\hline Sigma-370k $3 \min 3$ & 143585.64 & 44888.4 & 12087.9 & 3366.33 & 200561.94 & 82.3 \\
\hline Sigma-370k $3 \min 4$ & 78792.12 & 38361.6 & 17682.3 & 3699.63 & 134836.02 & 88.1 \\
\hline Sigma-370k $1 \mathrm{~min} 1$ & 290604.27 & 110822.4 & 43356.6 & 2499.75 & 444783.27 & 60.8 \\
\hline Sigma-370k $1 \mathrm{~min} 2$ & 391127.55 & 140059.8 & 34065.9 & 2766.39 & 565253.25 & 50.2 \\
\hline Sigma-370k $1 \mathrm{~min} 3$ & 336266.37 & 123409.8 & 35264.7 & 2333.1 & 494940.87 & 56.4 \\
\hline Sigma-370k $1 \mathrm{~min} 4$ & 257940.87 & 94705.2 & 37462.5 & 2733.06 & 390108.57 & 65.7 \\
\hline Sigma-370k $0.5 \mathrm{~min} 1$ & 400259.97 & 138661.2 & 39660.3 & 2866.38 & 578581.47 & 49.1 \\
\hline Sigma-370k $0.5 \mathrm{~min} 2$ & 407159.28 & 163902.6 & 50349.6 & 1766.49 & 621411.48 & 45.3 \\
\hline Sigma-370k $0.5 \mathrm{~min} 3$ & 558144.18 & 178155 & 39860.1 & 3566.31 & 776159.28 & 31.7 \\
\hline Sigma-370k $0.5 \mathrm{~min} 4$ & 366363.36 & 138461.4 & 47452.5 & 2533.08 & 552277.26 & 51.4 \\
\hline SPP-950k 5min 1 & 10232.31 & 1398.6 & 299.7 & 20064.66 & 11930.61 & 98.9 \\
\hline SPP-950k $5 \mathrm{~min} 2$ & 9132.42 & 1798.2 & 499.5 & 22164.45 & 11430.12 & 99.0 \\
\hline SPP-950k $5 \mathrm{~min} 3$ & 85458.12 & 17316 & 1698.3 & 3033.03 & 104472.42 & 90.8 \\
\hline SPP-950k 5min 4 & 28397.16 & 5927.4 & 699.3 & 4299.57 & 35023.86 & 96.9 \\
\hline SPP-950k 3min 1 & 73359.33 & 24175.8 & 5394.6 & 4166.25 & 102929.73 & 90.9 \\
\hline SPP-950k 3min 2 & 185081.49 & 51015.6 & 7492.5 & 2366.43 & 243589.59 & 78.6 \\
\hline SPP-950k $3 \min 3$ & 146885.31 & 24975 & 3496.5 & 2566.41 & 175356.81 & 84.6 \\
\hline SPP-950k $3 \min 4$ & 77758.89 & 27639 & 7892.1 & 3666.3 & 113289.99 & 90.0 \\
\hline SPP-950k $1 \mathrm{~min} 1$ & 254807.85 & 77122.8 & 20079.9 & 4932.84 & 352010.55 & 69.0 \\
\hline SPP-950k $1 \mathrm{~min} 2$ & 328900.44 & 107359.2 & 19980 & 2233.11 & 456239.64 & 59.8 \\
\hline SPP-950k $1 \mathrm{~min} 3$ & 362230.44 & 115950.6 & 18381.6 & 2199.78 & 496562.64 & 56.3 \\
\hline SPP-950k $1 \mathrm{~min} 4$ & 255841.08 & 66799.8 & 9990 & 2433.09 & 332630.88 & 70.7 \\
\hline SPP-950k 0.5min 1 & 369063.09 & 123210 & 30569.4 & 2266.44 & 522842.49 & 54.0 \\
\hline SPP-950k 0.5min 2 & 430590.27 & 123676.2 & 21978 & 2233.11 & 576244.47 & 49.3 \\
\hline SPP-950k 0.5min 3 & 447221.94 & 176290.2 & 43956 & 2833.05 & 667468.14 & 41.2 \\
\hline SPP-950k 0.5min 4 & 396560.34 & 107825.4 & 20379.6 & 2833.05 & 524765.34 & 53.8 \\
\hline
\end{tabular}

a,b The doublets and triplets were multiplied by the 2 and 3 , respectively, in the "sum" calculation. ${ }^{c}$ The "other" counts were not included in the "sum." 
Table S4. Average counts from the flow cytometry data presented in Figures S8-S24 and Table S3.

\begin{tabular}{|c|c|c|c|c|c|c|}
\hline sample information & singlets $/ \mathrm{mL}$ & doublets $/ \mathrm{mL}^{\mathrm{a}}$ & triplets $/ \mathrm{mL}^{\mathrm{b}}$ & other/mLc & sum/mL & $\begin{array}{l}\% \\
\text { removal }\end{array}$ \\
\hline PS stock suspension & 792421 & 289830 & 53806 & 6566 & 1136057 & 0.0 \\
\hline Sigma-93k 0.5min & 138594 & 51099 & 29645 & 19723 & 219339 & 80.7 \\
\hline Sigma-93k $1 \mathrm{~min}$ & 97165 & 36513 & 22103 & 19740 & 155782 & 86.3 \\
\hline Sigma-93k 3min & 29722 & 10323 & 3946 & 18065 & 43991 & 96.1 \\
\hline Sigma-93k 5min & 11082 & 2880 & 824 & 19756 & 14787 & 98.7 \\
\hline P\&G-590k 0.5min & 349948 & 95171 & 17033 & 2875 & 462153 & 59.3 \\
\hline P\&G-590k $1 \mathrm{~min}$ & 200580 & 48402 & 7393 & 2508 & 256374 & 77.4 \\
\hline P\&G-590k 3min & 63244 & 10356 & 1374 & 2258 & 74974 & 93.4 \\
\hline P\&G-590k 5min & 14457 & 1415 & 225 & 2491 & 16097 & 98.6 \\
\hline Sigma-370k 0.5min & 432982 & 154795 & 44331 & 2683 & 632107 & 444.4 \\
\hline Sigma-370k $1 \mathrm{~min}$ & 318985 & 117249 & 37537 & 2583 & 473771 & 58.3 \\
\hline Sigma-370k 3min & 125462 & 45821 & 15634 & 3175 & 186918 & 83.5 \\
\hline Sigma-370k 5min & 62902 & 19297 & 5070 & 2625 & 87269 & 92.3 \\
\hline SPP-950k 0.5min & 410859 & 132750 & 29221 & 2541 & 572830 & 49.6 \\
\hline SPP-950k $1 \mathrm{~min}$ & 300445 & 91808 & 17108 & 2950 & 409361 & 64.0 \\
\hline SPP-950k 3 min & 120771 & 31951 & 6069 & 3191 & 158792 & 86.0 \\
\hline SPP-950K 5 min & 33305 & 6610 & 799 & 12390 & 40714 & 96.4 \\
\hline
\end{tabular}

a,b The doublets and triplets were multiplied by the 2 and 3 , respectively, in the "sum" calculation. ${ }^{c}$ The "other" counts were not included in the "sum." 


\section{Flow cytometry raw data plots}
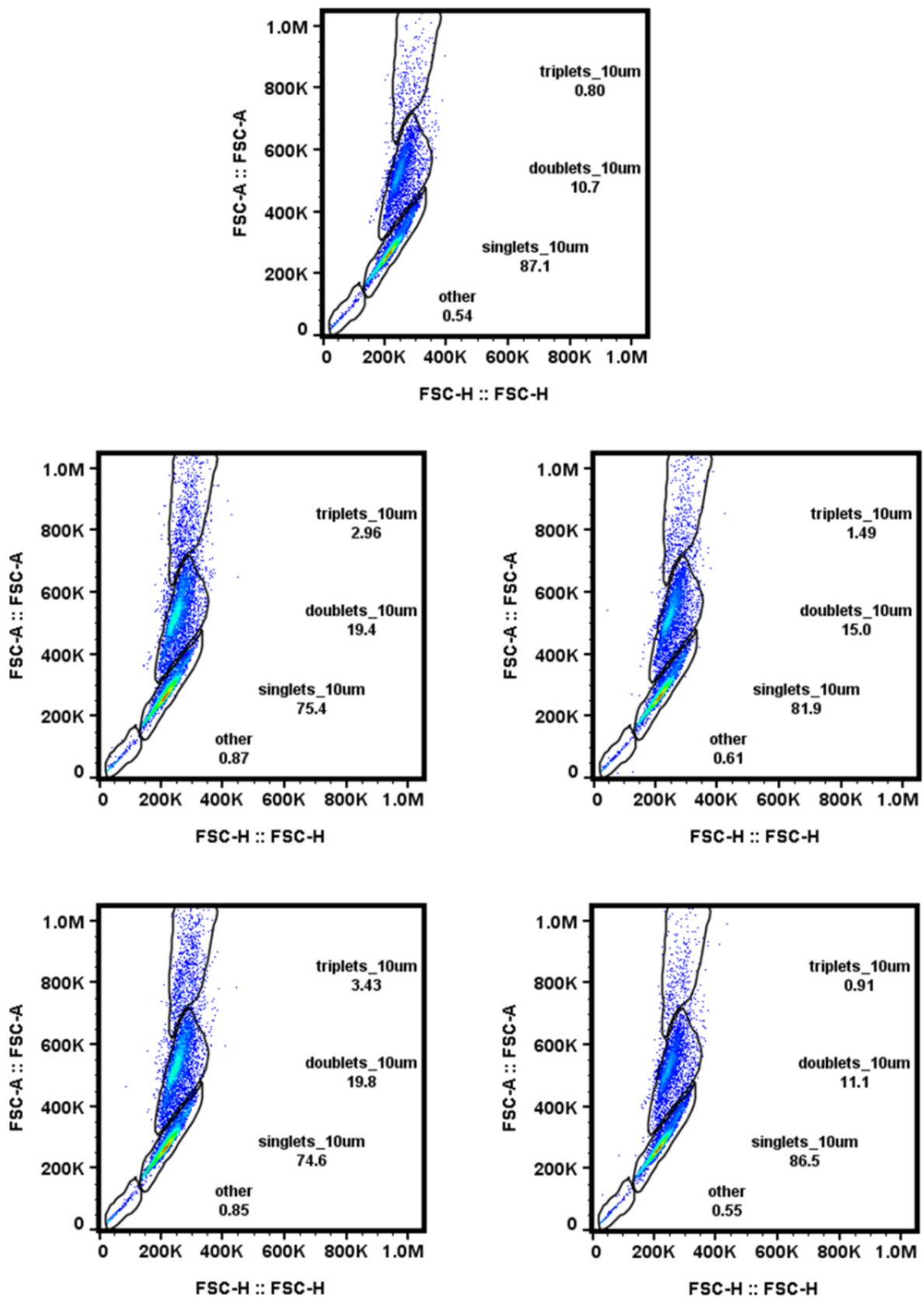

Figure S8. Flow cytometry data for stock PS microplastics suspensions. 

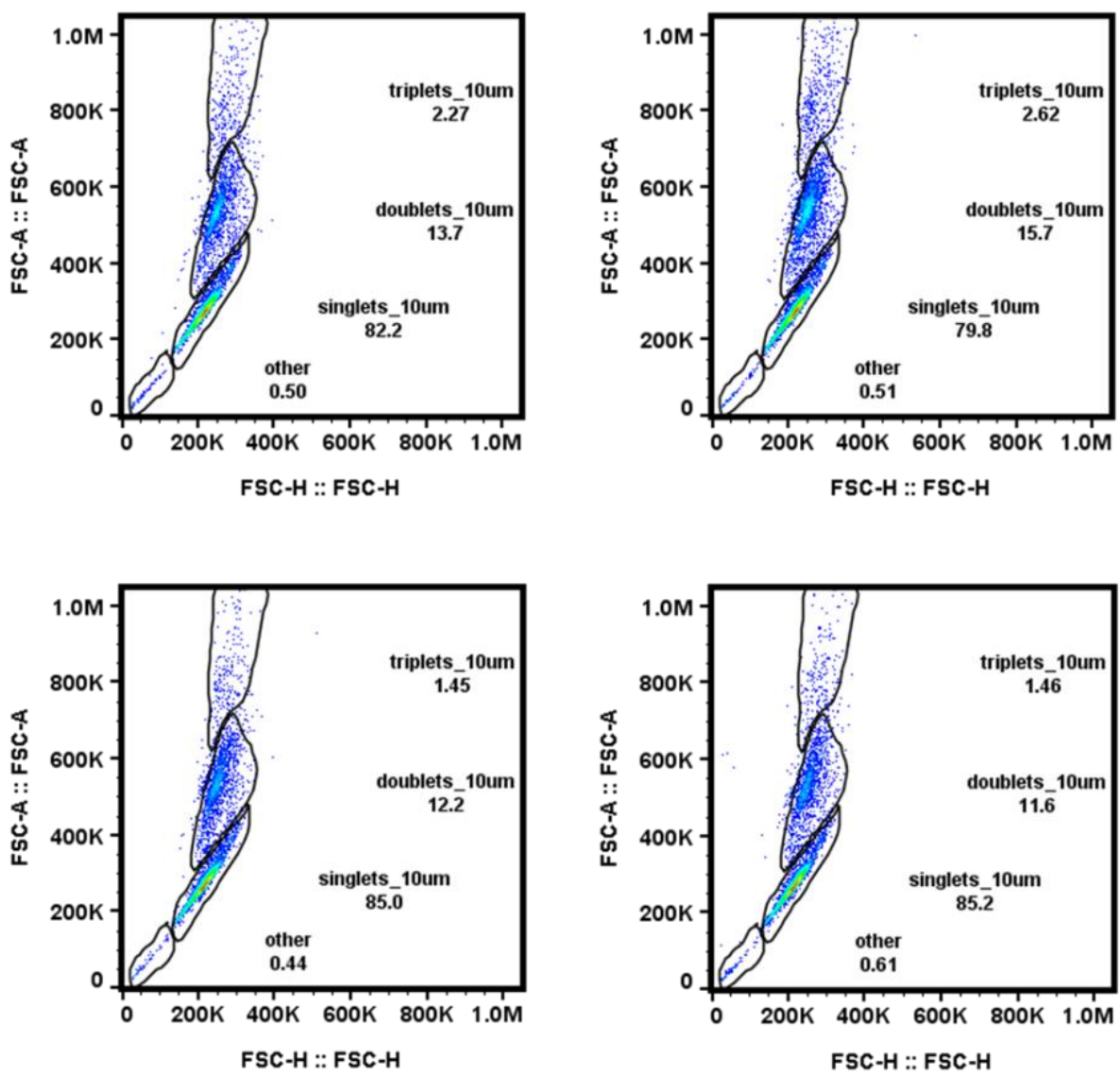

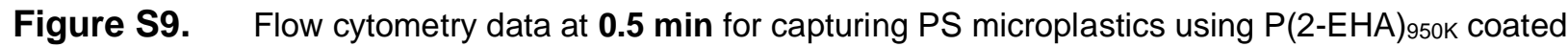
onto beads 

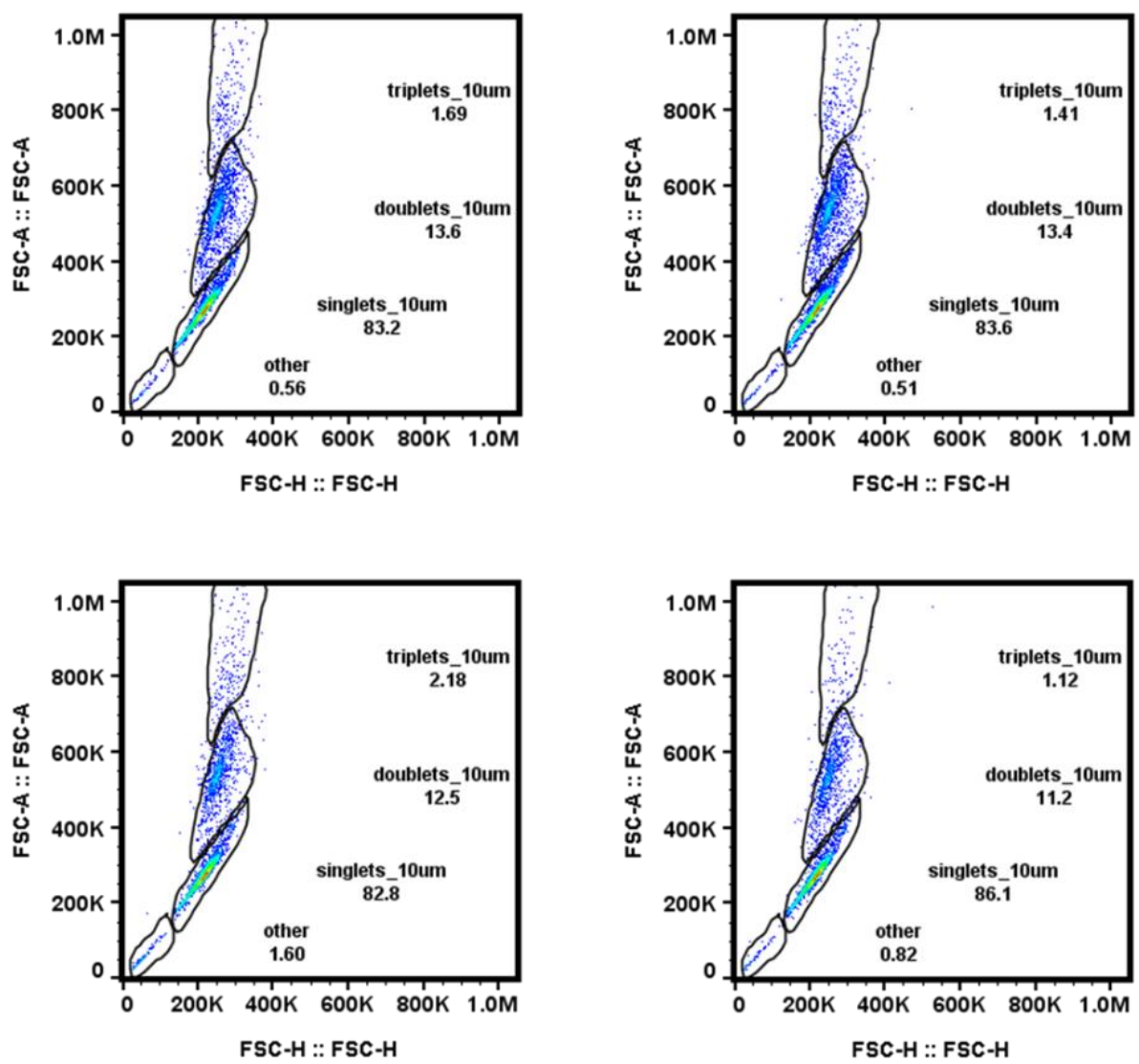

Figure S10. Flow cytometry data at $\mathbf{1}$ min for capturing PS microplastics using $\mathrm{P}(2-\mathrm{EHA})_{950 \mathrm{~K}}$ coated onto beads 

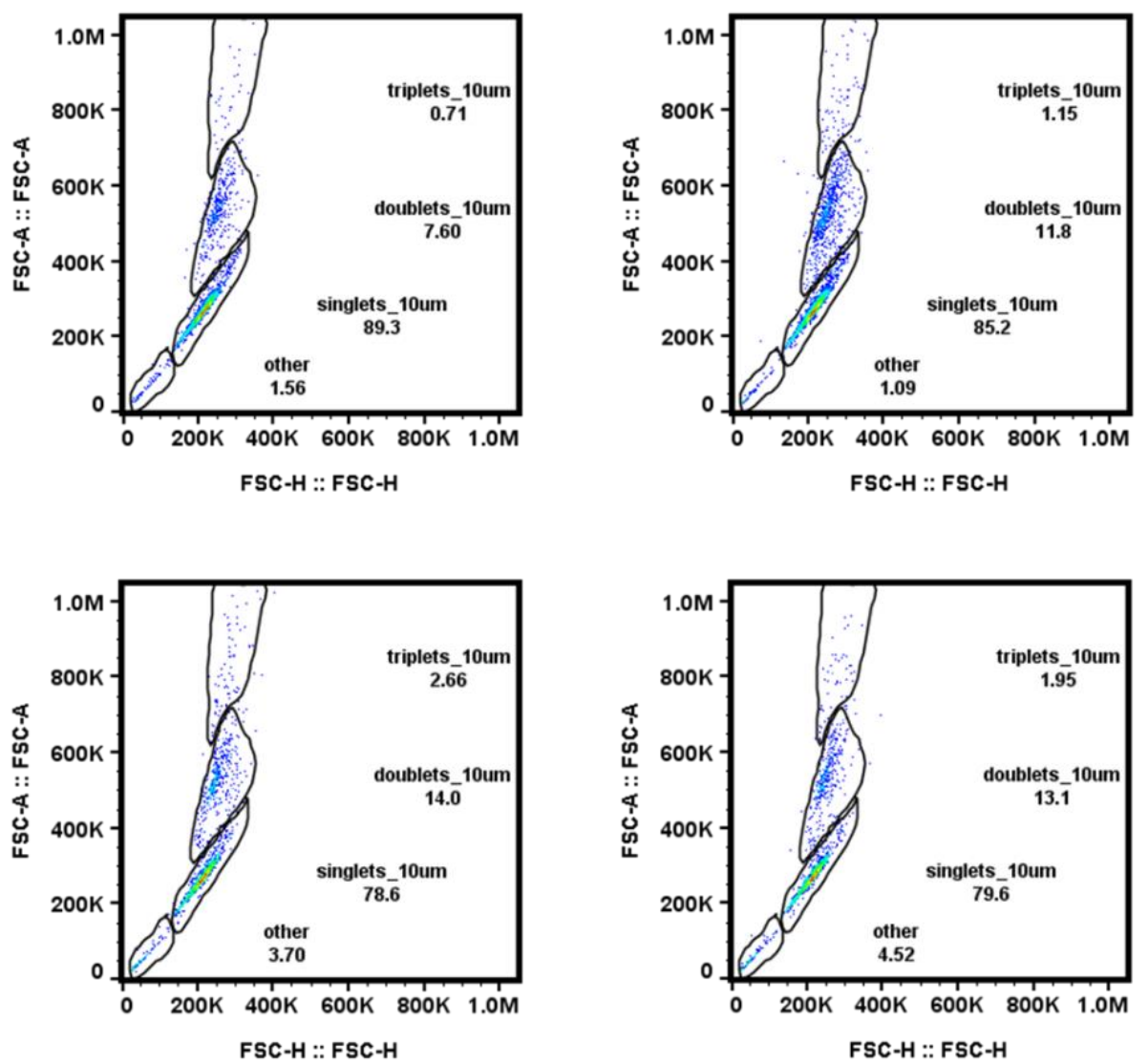

Figure S11. Flow cytometry data at $\mathbf{3}$ min for capturing PS microplastics using P(2-EHA)950k coated onto beads 

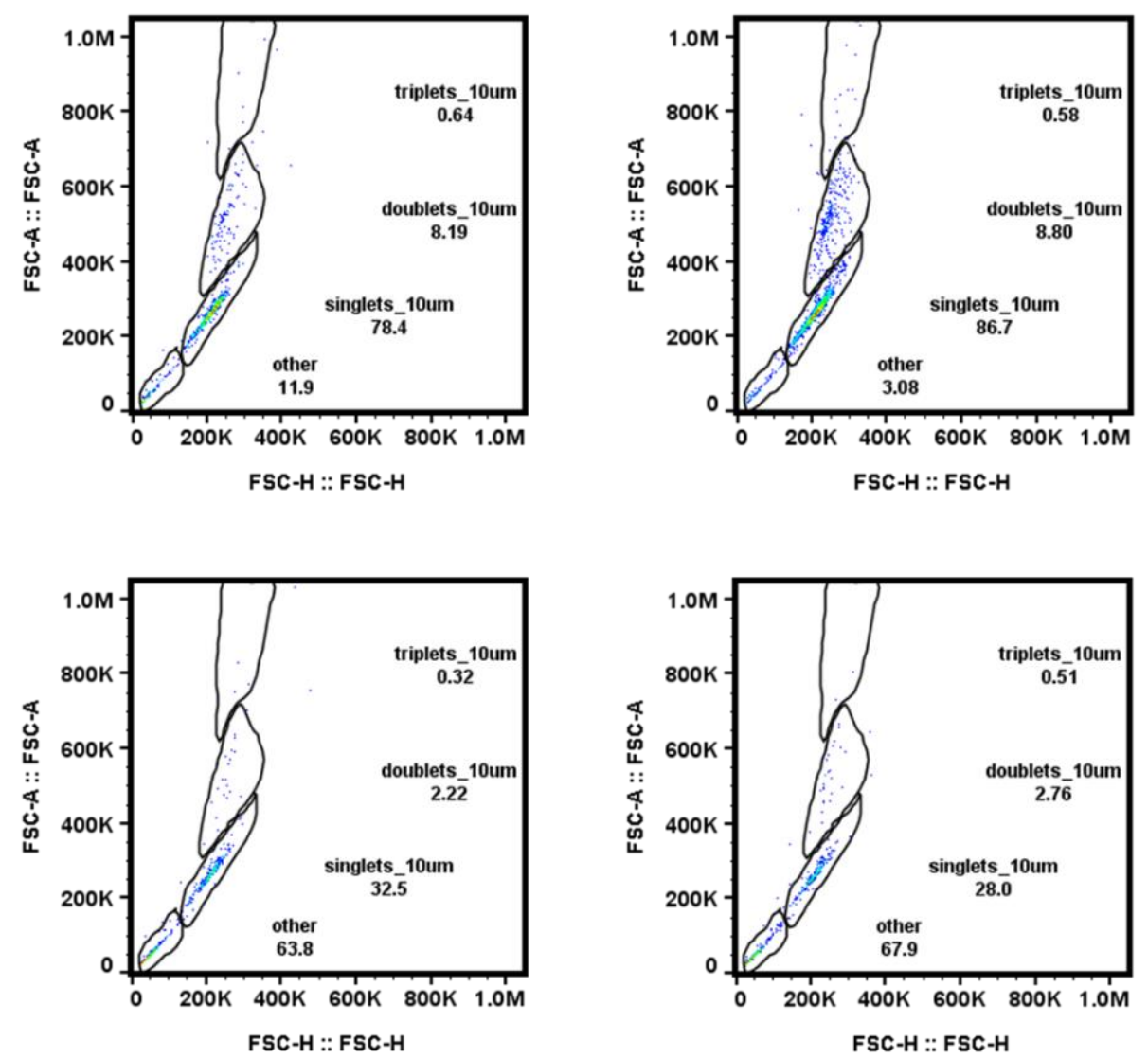

Figure S12. Flow cytometry data at $\mathbf{5}$ min for capturing PS microplastics using $\mathrm{P}(2-\mathrm{EHA})_{950 \mathrm{~K}}$ coated onto beads 

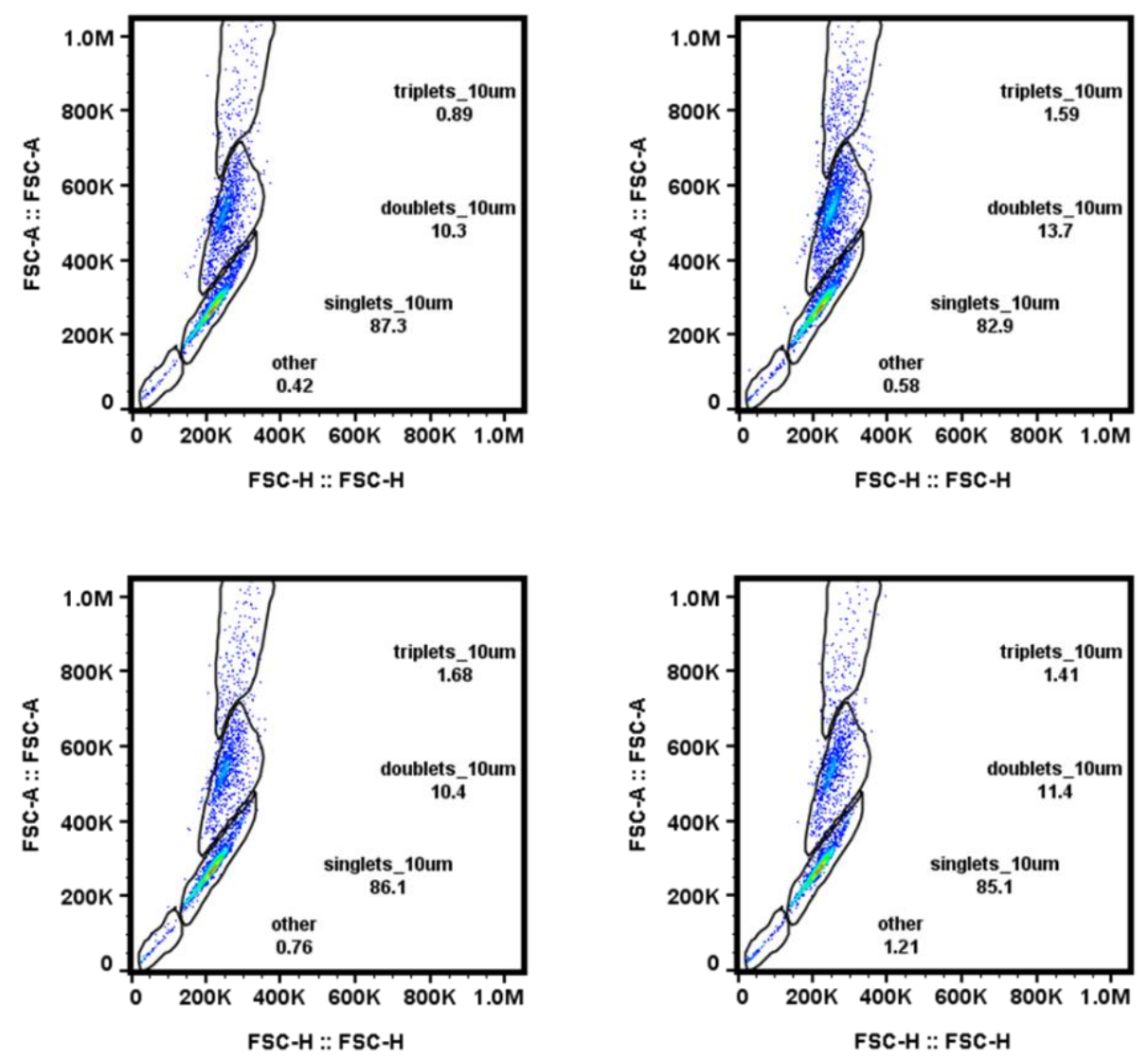

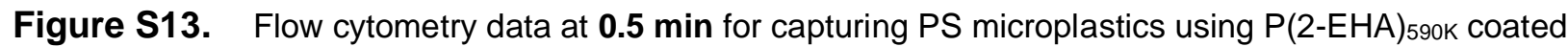
onto beads 

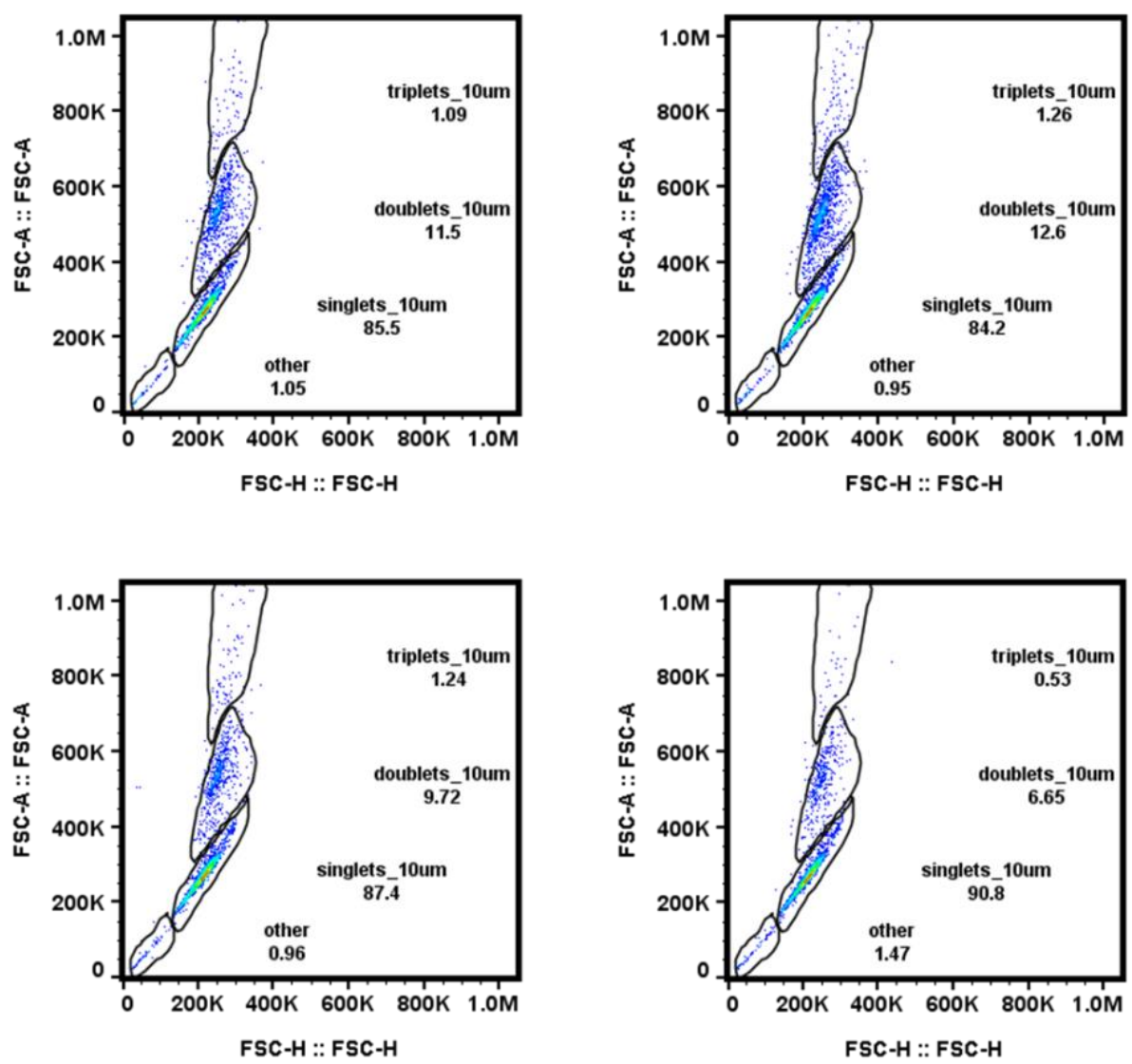

Figure S14. Flow cytometry data at 1 min for capturing PS microplastics using $P(2-E H A)_{590 k}$ coated onto beads 

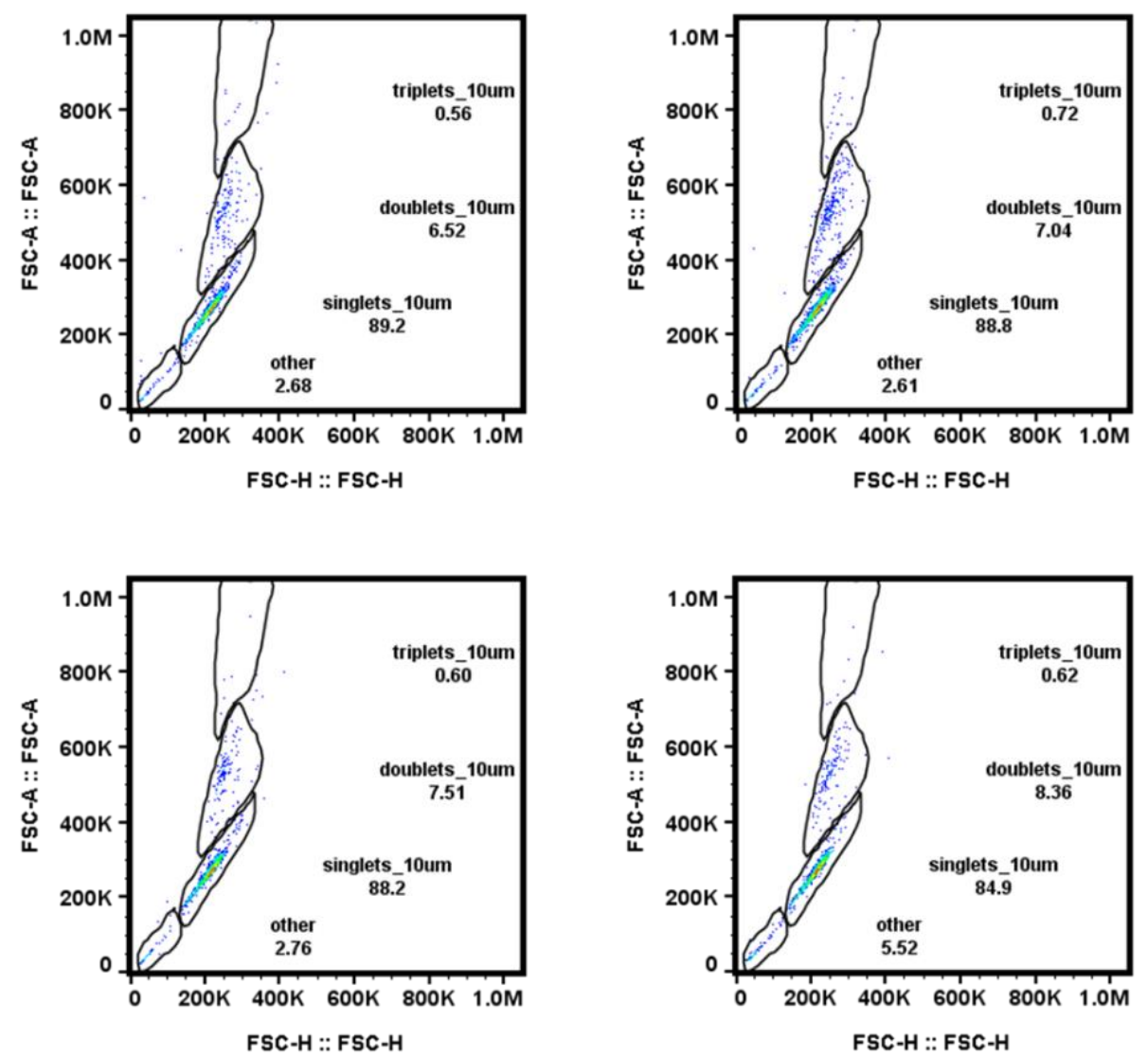

Figure S15. Flow cytometry data at $\mathbf{3}$ min for capturing PS microplastics using P(2-EHA) $)_{590 k}$ coated onto beads 

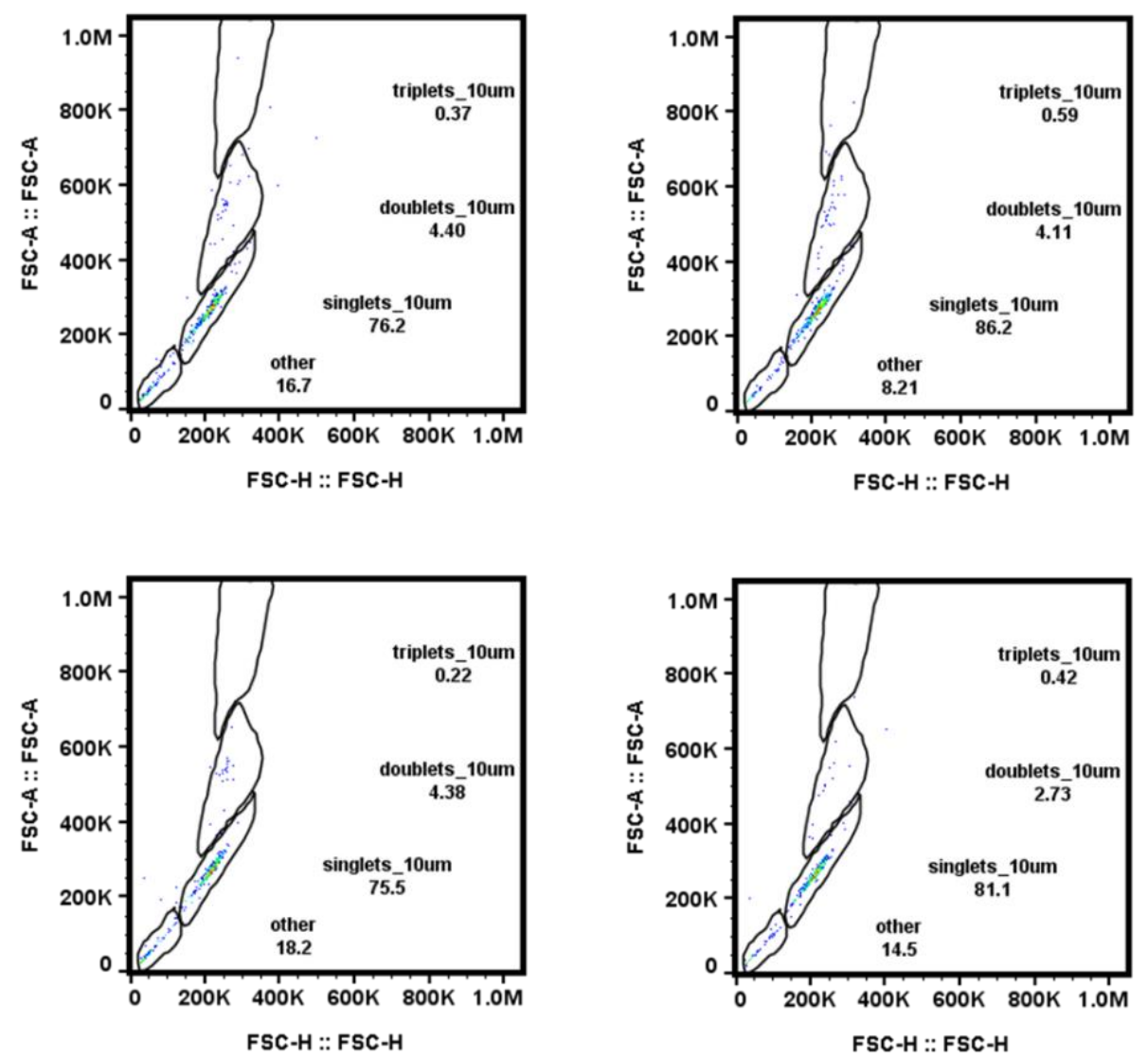

Figure S16. Flow cytometry data at $\mathbf{5}$ min for capturing PS microplastics using P(2-EHA)590k coated onto beads 

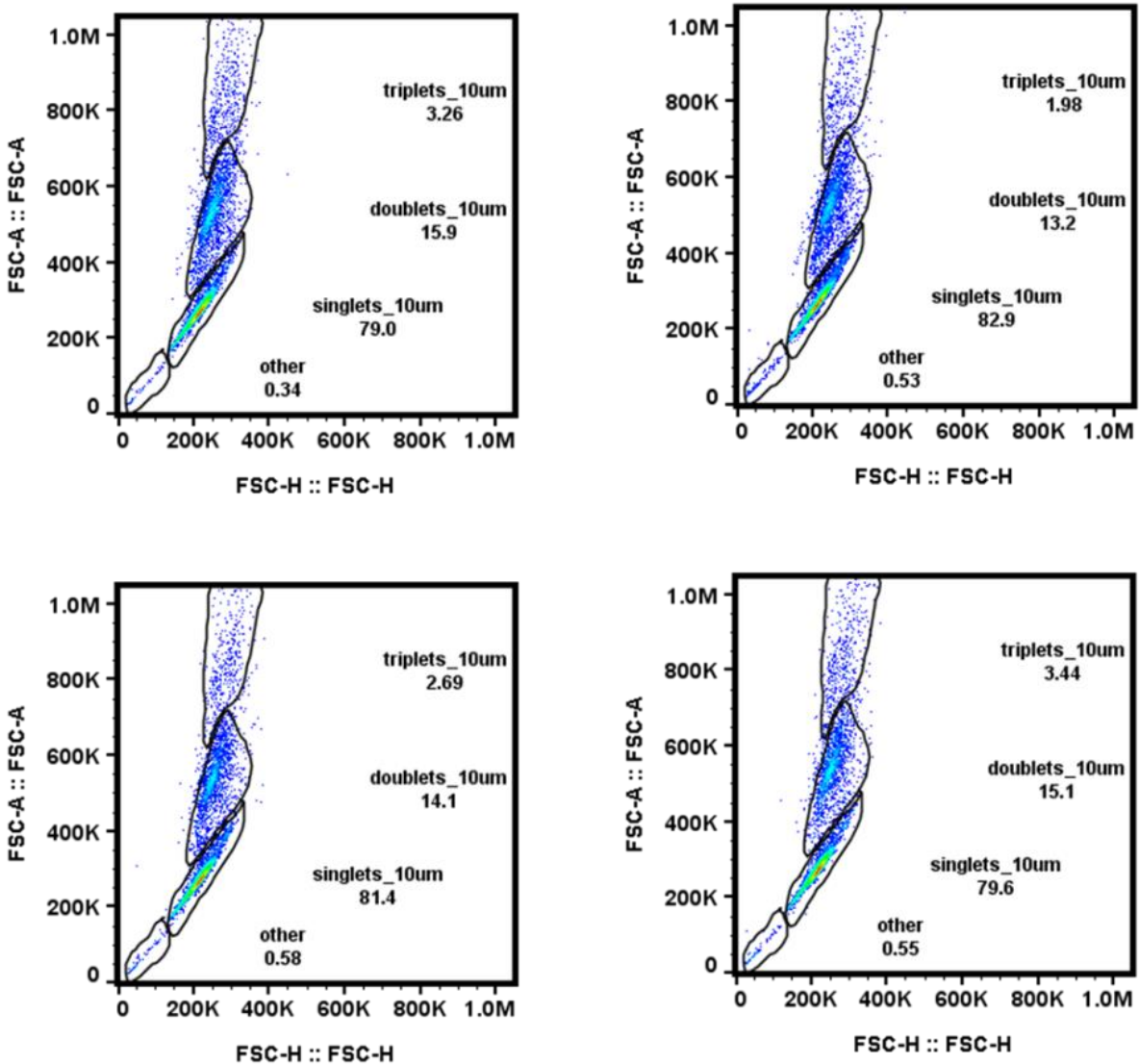

Figure S17. Flow cytometry data at $\mathbf{0 . 5} \mathbf{~ m i n}$ for capturing PS microplastics using $\mathrm{P}(2-\mathrm{EHA})_{370 \mathrm{~K} \text { coated }}$ onto beads 

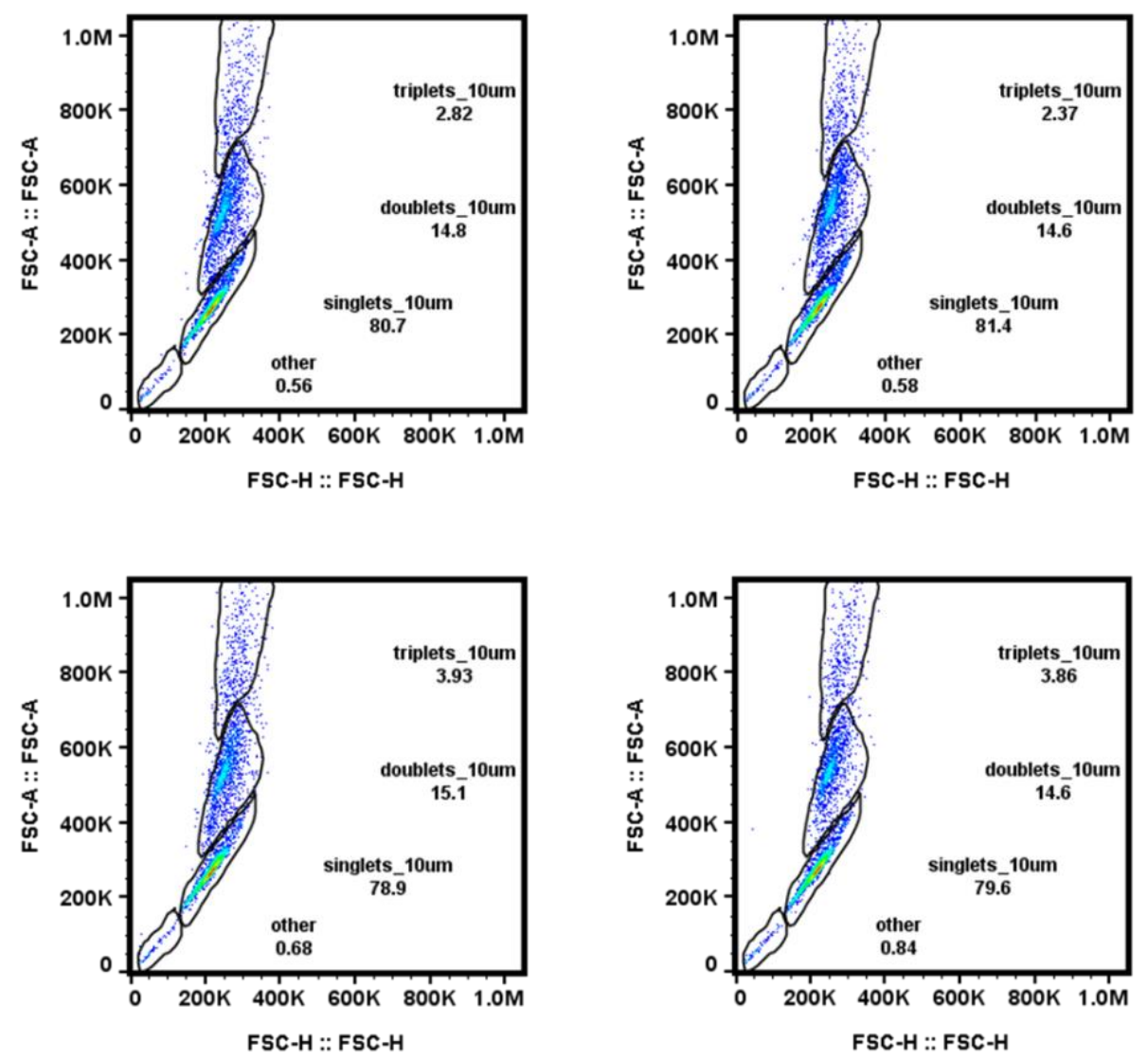

Figure S18. Flow cytometry data at $\mathbf{1}$ min for capturing PS microplastics using $\mathrm{P}(2-\mathrm{EHA})_{370 \mathrm{~K} \text { coated }}$ onto beads 

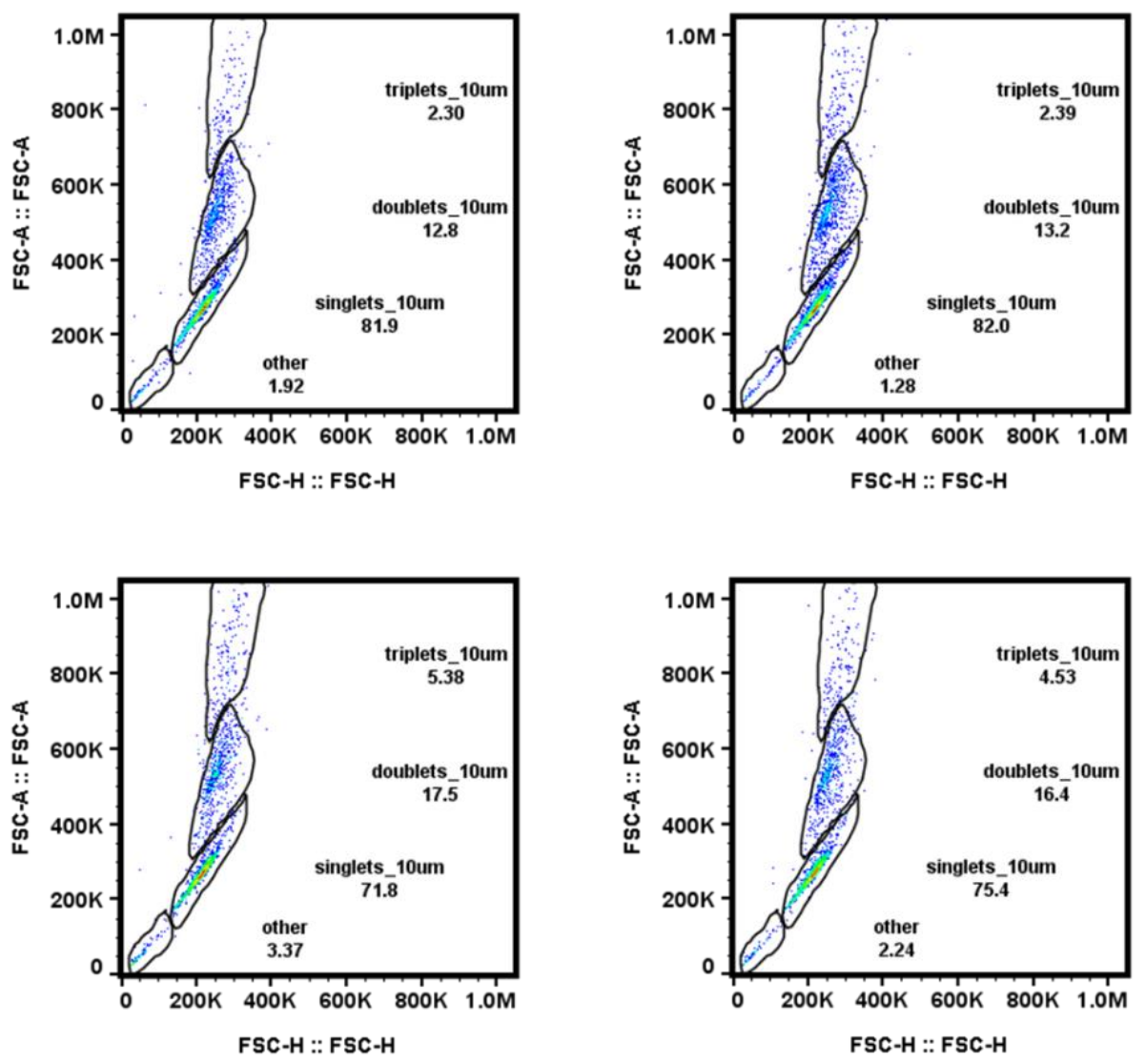

Figure S19. Flow cytometry data at $\mathbf{3}$ min for capturing PS microplastics using $\mathrm{P}(2-\mathrm{EHA})_{370 \mathrm{~K}}$ coated onto beads 

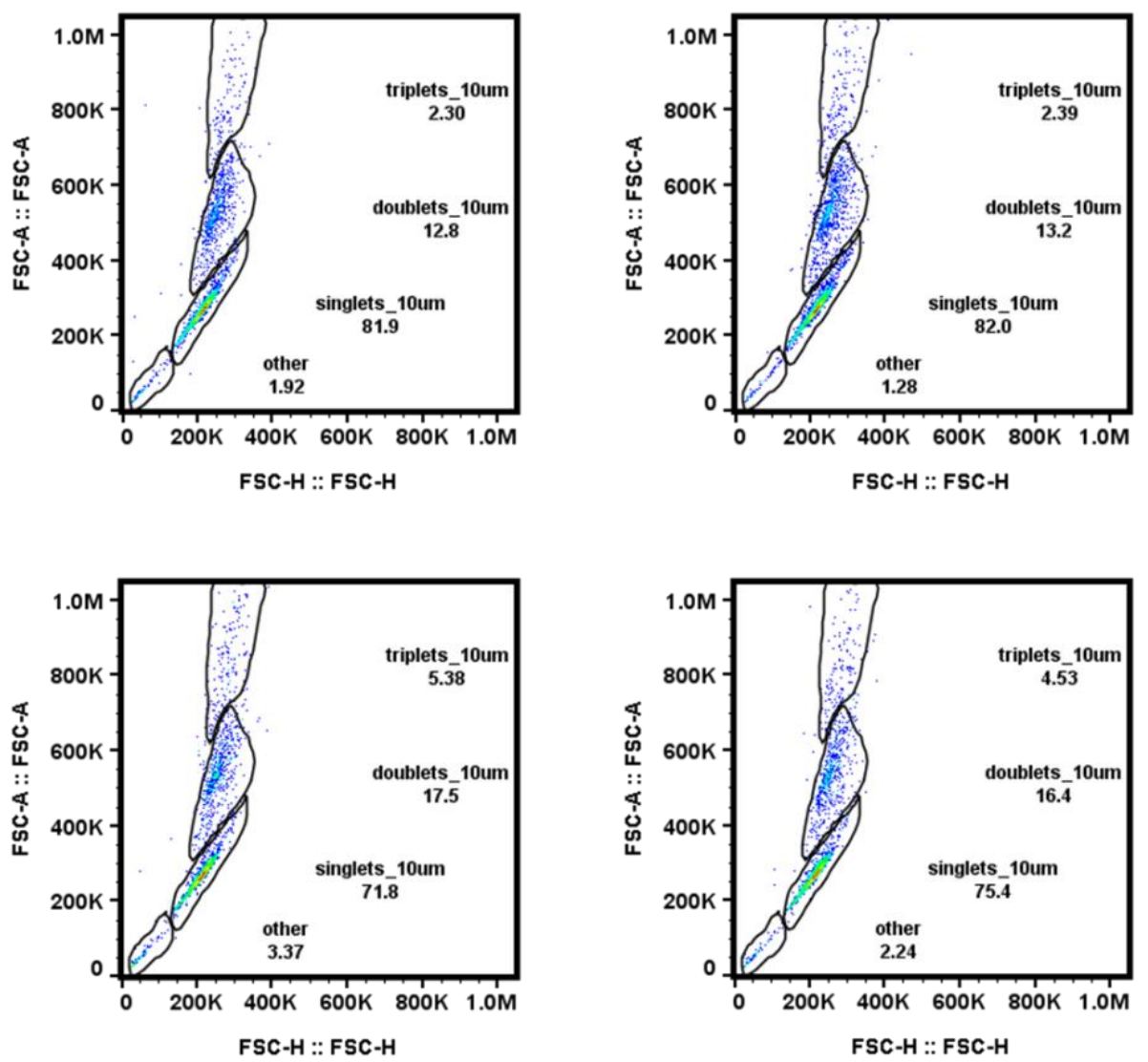

Figure S20. Flow cytometry data at $\mathbf{5}$ min for capturing PS microplastics using $\mathrm{P}(2-\mathrm{EHA})_{370 \mathrm{~K}}$ coated onto beads 

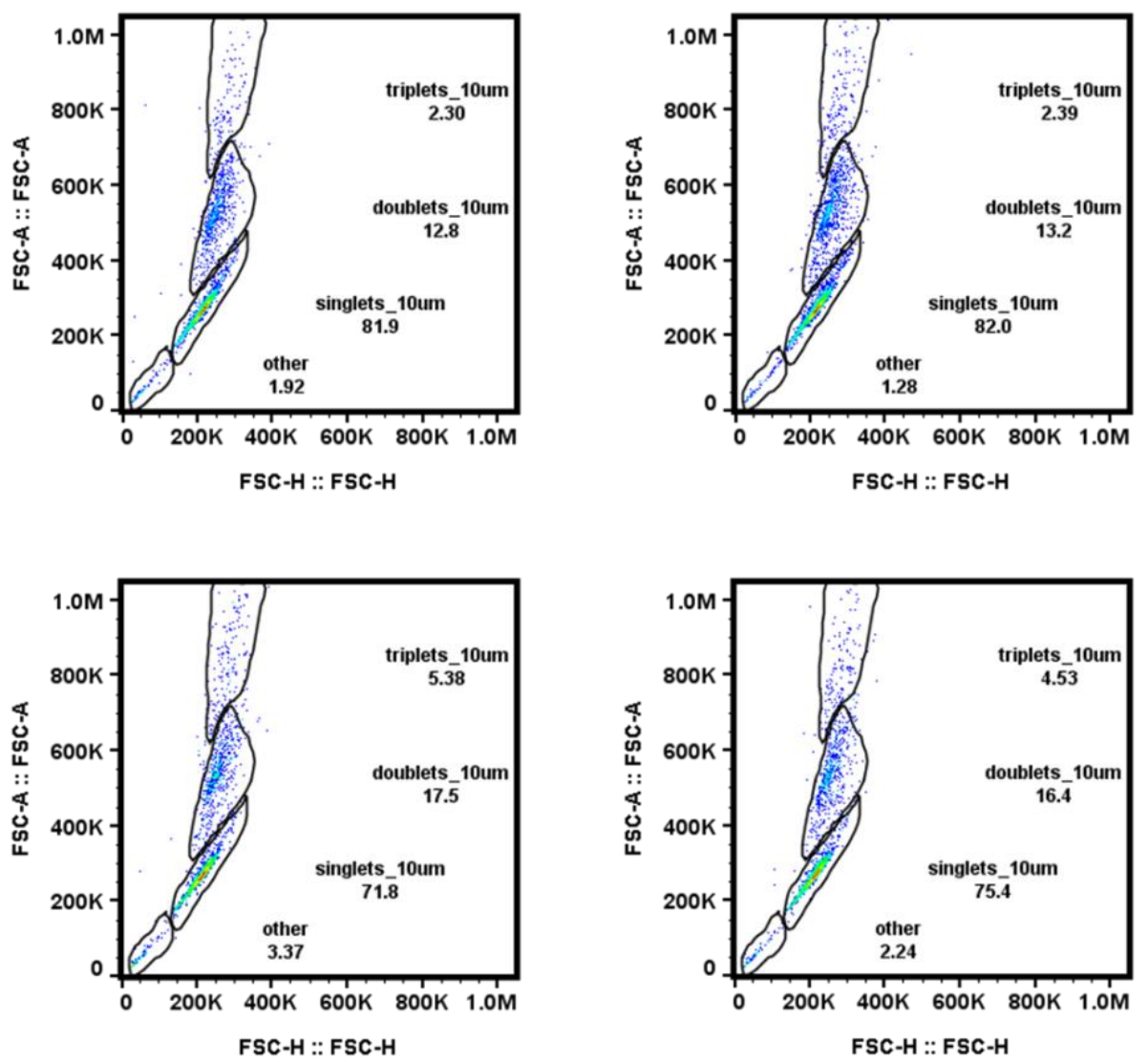

Figure S21. Flow cytometry data at $\mathbf{0 . 5} \mathbf{~ m i n}$ for capturing PS microplastics using $\mathrm{P}(2-\mathrm{EHA})_{9 з к}$ coated onto beads 

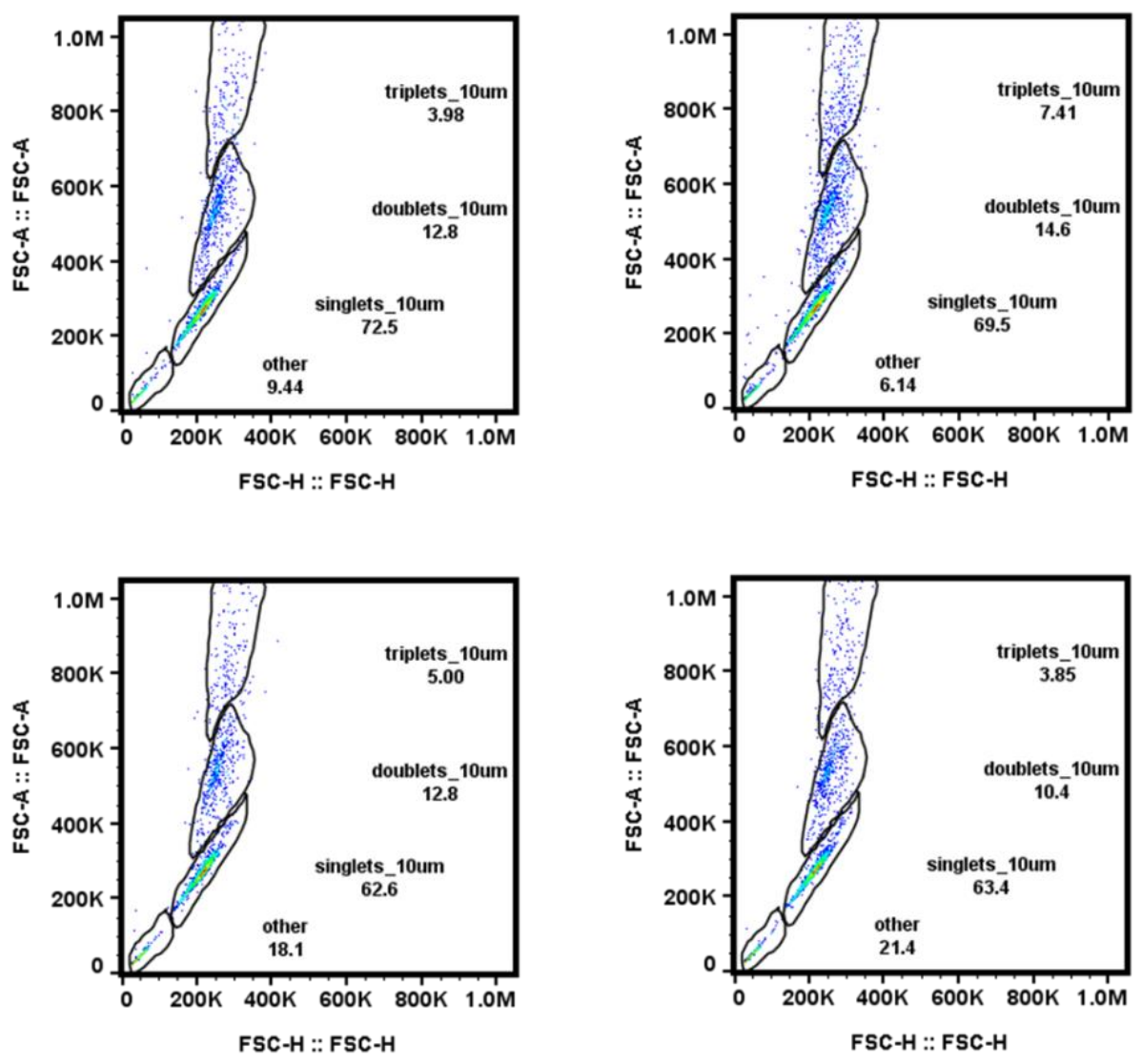

Figure S22. Flow cytometry data at 1 min for capturing PS microplastics using P(2-EHA)93k coated onto beads 

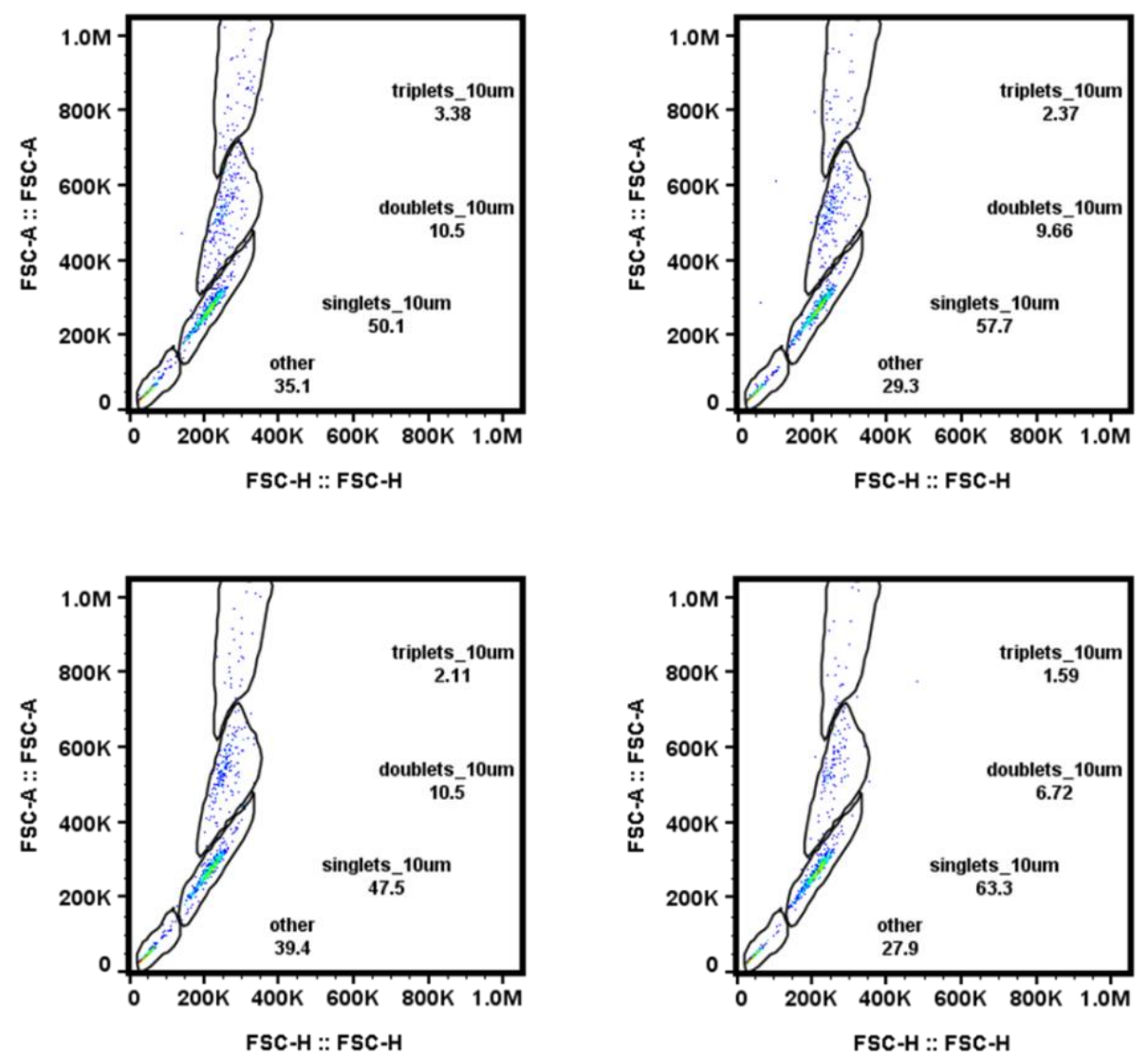

Figure S23. Flow cytometry data at $\mathbf{3}$ min for capturing PS microplastics using $\mathrm{P}(2-\mathrm{EHA})_{93 \mathrm{~K}}$ coated onto beads 

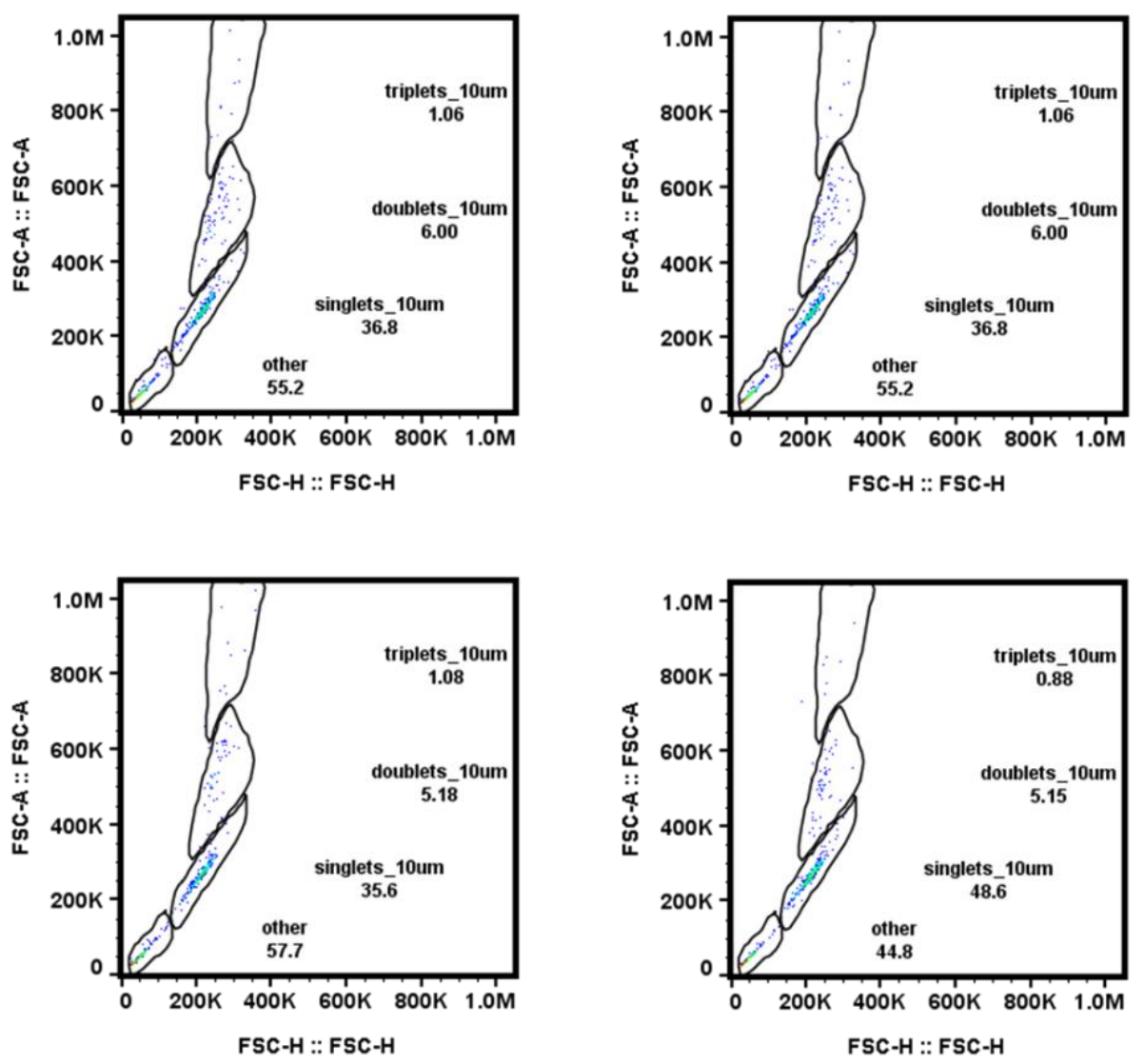

Figure S24. Flow cytometry data at $\mathbf{5}$ min for capturing PS microplastics using P(2-EHA) 9зк coated onto beads 


\section{E. Microplastics removal efficiency without EtOH}

Five PS suspensions in $\mathrm{H}_{2} \mathrm{O}(1.0 \mathrm{mg} / \mathrm{mL})$ were prepared by adding $\mathrm{PS}(1.0 \mathrm{mg}, 10 \mu \mathrm{m})$ and $\mathrm{H}_{2} \mathrm{O}(1.00 \mathrm{~mL})$ to a $4 \mathrm{~mL}$ vial followed by vortex mixing for $1 \mathrm{~min}$.

Four of the five suspensions prepared were used for the removal experiment. To each of the four

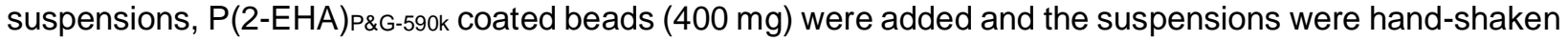
at 3 shakes per second for $5 \mathrm{~min}$. After hand-shaking, EtOH $(200 \mu \mathrm{L})$ was added to each sample to homogenize the suspension, and then a needle (18 gauge) and syringe $(3 \mathrm{~mL})$ was used to transfer the remaining microplastic suspension into a $1.5 \mathrm{~mL}$ Eppendorf tube, which was stored in the refrigerator until quantification $(\sim 10 \mathrm{~h})$.

Note: Julie Rieland performed the hand-shaking on replicates number 1 and 2 while Takunda Chazovachii performed the hand-shaking on replicates number 3 and 4.

Table S5. Summary of flow cytometry data for experiments with EtOH added before analysis. Note that the raw data was first multiplied by a factor of 33.3 to convert the $30 \mu \mathrm{L}$ injection volume to a count $/ \mathrm{mL}$ for this table.

\begin{tabular}{|l|l|l|l|l|l|l|l|l|}
\hline sample & singlets/mL & doublets $/ \mathbf{m L}^{\mathrm{a}}$ & triplets $/ \mathbf{m L}^{\mathrm{b}}$ & other/mL & sum/mL & average & stdev & $\%$ removal \\
\hline P\&G-590k 1 & 3640 & 400 & 120 & 3240 & 4160 & & & \\
P\&G-590k 2 & 1080 & 240 & 0 & 4240 & 1320 & & \\
P\&G-590k 3 & 1040 & 320 & 240 & 3600 & 1600 & & & \\
P\&G-590k 4 & 480 & 400 & 360 & 4080 & 1240 & 2080 & 1208 & 99.83 \\
\hline \hline PS stock 1 & 902640 & 330400 & 37080 & 6000 & 1270120 & & & \\
PS stock 2 & 952080 & 267360 & 27840 & 4560 & 1247280 & & \\
PS stock 3 & 964240 & 261520 & 29280 & 5640 & 1255040 & & & \\
PS stock 4 & 857440 & 316160 & 24960 & 5000 & 1198560 & 1242750 & 26802 & 0 \\
\hline
\end{tabular}

a,b The doublets and triplets were multiplied by the 2 and 3 , respectively, in the "sum" calculation. ${ }^{c}$ The "other" counts were not included in the "sum." 

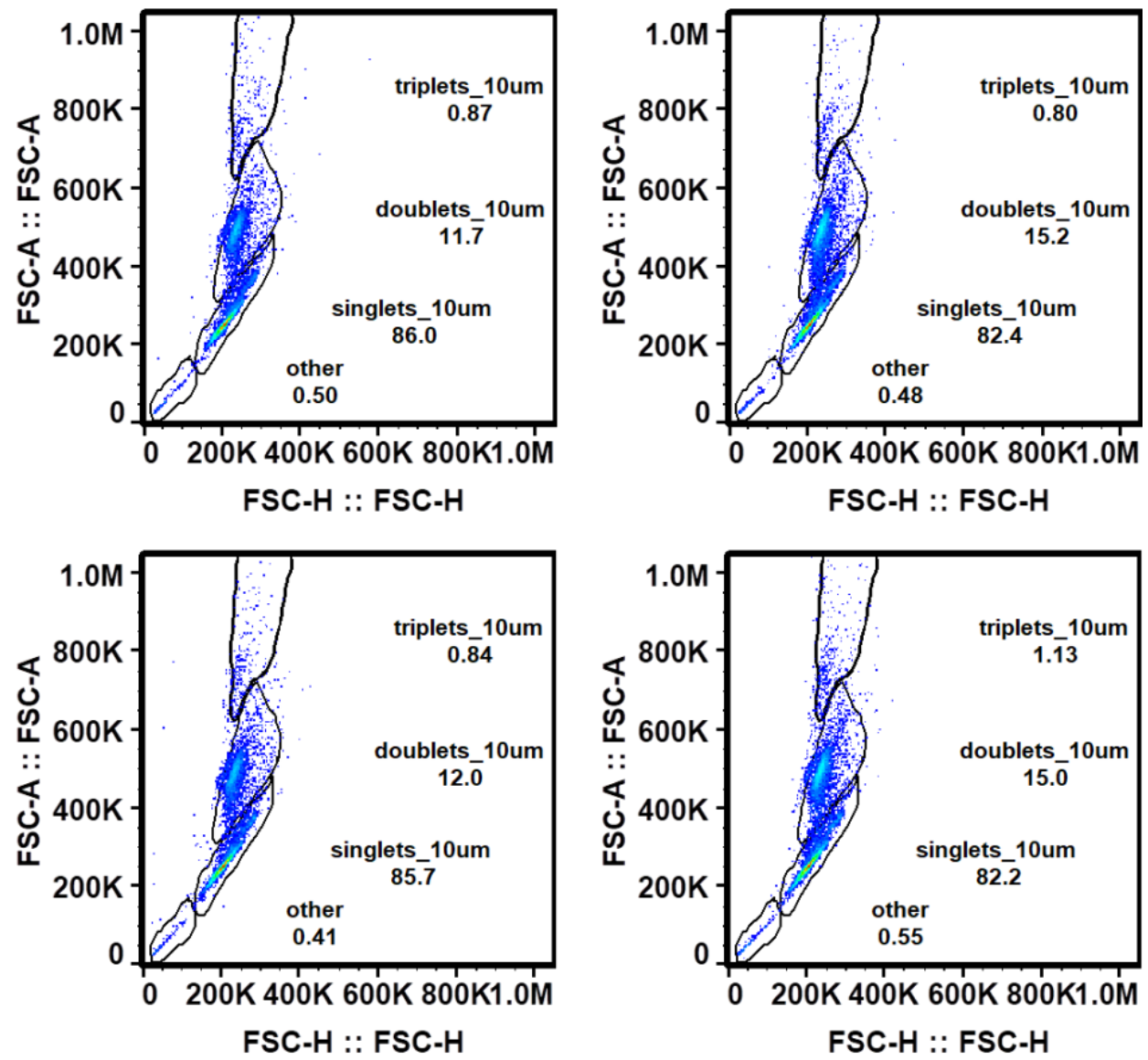

Figure S25. Flow cytometry data for PS stock solution with EtOH added for sample analysis only. 

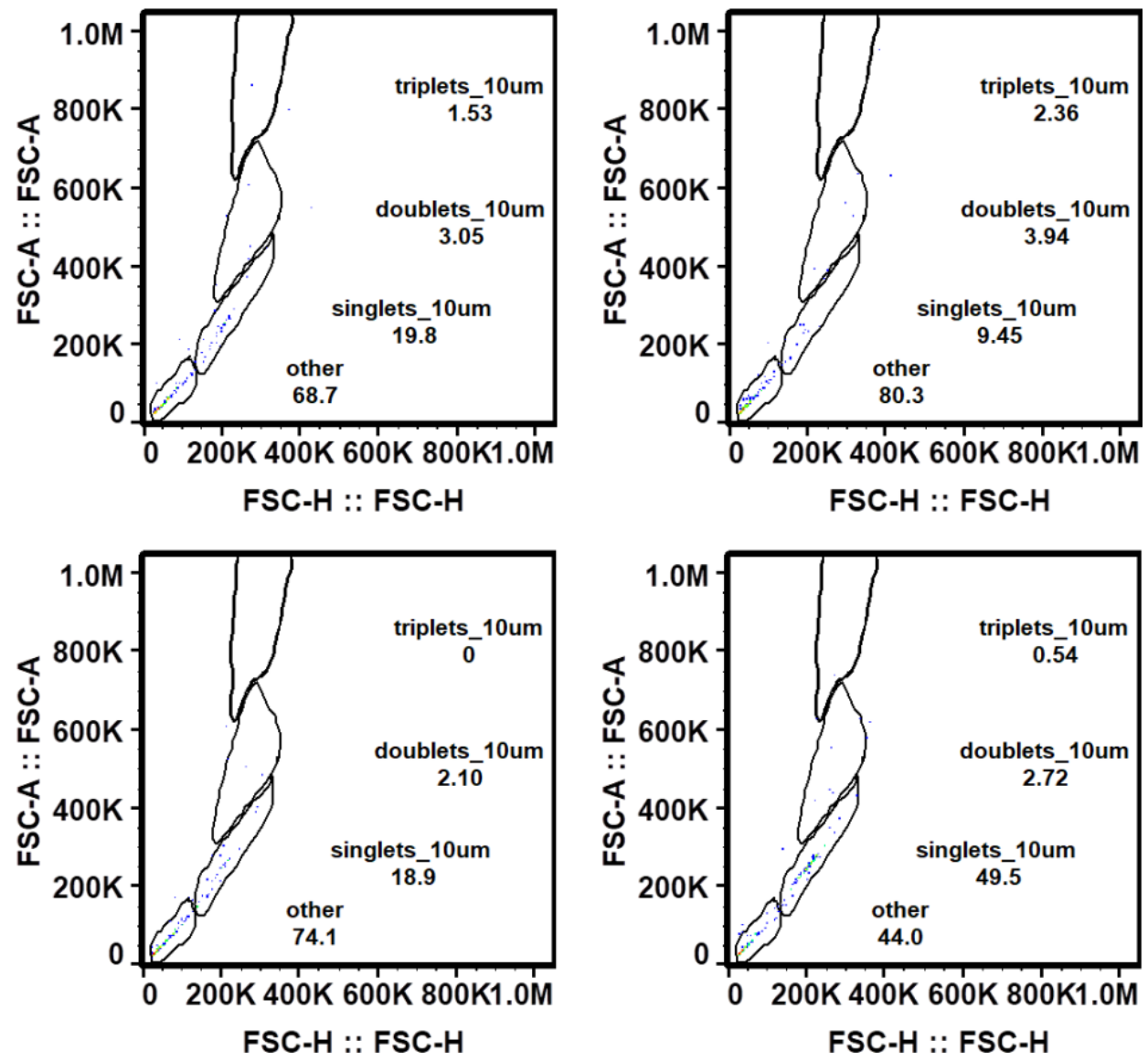

Figure S26. Flow cytometry data at $\mathbf{5}$ min for capturing PS microplastics using P(2-EHA)590k coated onto beads with $\mathrm{EtOH}$ added only for analysis. 


\section{Testing MPs removal using glass slides}

\section{A. Coating glass slides}

Onto five glass slides $(1.2 \times 4.0 \mathrm{~cm})$, a P(2-EHA)P\&G_590k solution in THF $(10 \mu \mathrm{L}, 5 \% \mathrm{w} / \mathrm{v})$ was dispensed using a micropipette. The slides were then held for $2 \mathrm{~min}$ at room temperature and then further dried at 125 ${ }^{\circ} \mathrm{C}$ in the oven for $2 \mathrm{~min}$. The slides were then cooled to room temperature for about $5 \mathrm{~min}$.

\section{B. Preparing microplastics suspensions}

Microplastic suspensions (final conc $=2.0 \mathrm{mg} / \mathrm{mL}$ ) of nylon $(30 \mu \mathrm{m})$, poly(ethylene) $(\mathrm{PE}, 50 \mu \mathrm{m})$, micronized rubber $(\mathrm{MR}, 100 \mu \mathrm{m})$, and poly(ethylene terephthalate) $(300 \mu \mathrm{m})$ were prepared by adding the microplastics $(10 \mathrm{mg})$ and ultrafiltered $\mathrm{H}_{2} \mathrm{O}(5.00 \mathrm{~mL})$ to $20 \mathrm{~mL}$ vials followed by vortex mixing for $1 \mathrm{~min}$.

\section{Microplastics capture}

To each microplastics suspension, an adhesive-coated glass slide was added, and the suspensions were hand-shaken for 5 min at 3 shakes per second. Thereafter, the glass slides were removed using tweezers and washed with $\mathrm{DI} \mathrm{H}_{2} \mathrm{O}(20 \mathrm{~mL})$ using a squirt bottle to remove unadhered MPs. The slides were then airdried for $30 \mathrm{~min}$ and analyzed using optical microscopy.

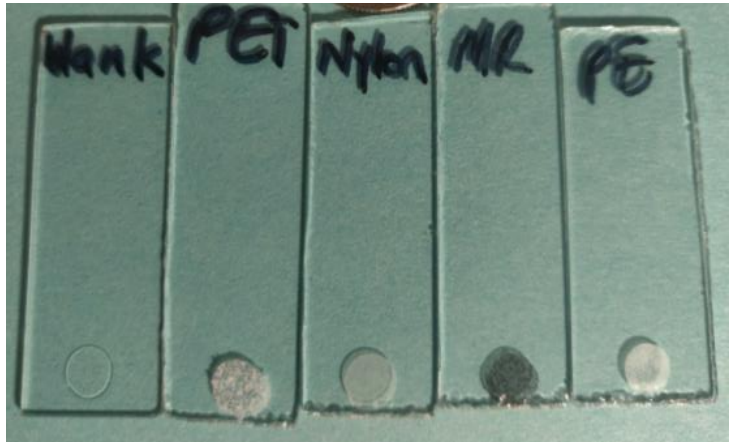

Figure S27. Glass slides with drop-cast P(2-EHA)P\&G_590k after microplastics capture. 

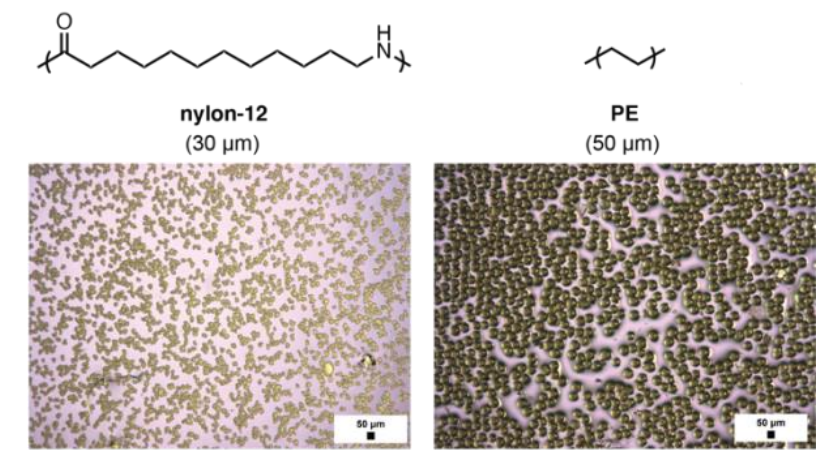

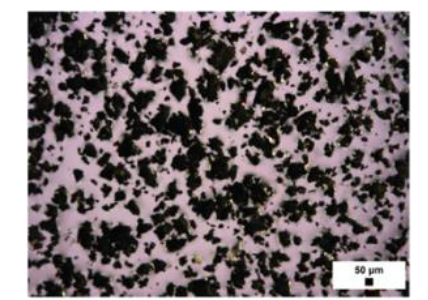

micronized rubber (blend)

$(100 \mu \mathrm{m})$

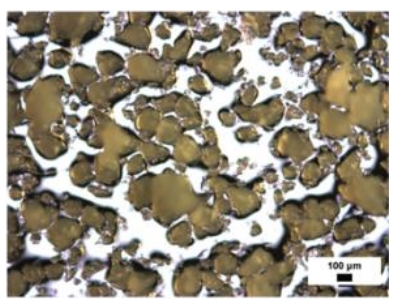

PET

$(300 \mu \mathrm{m})$

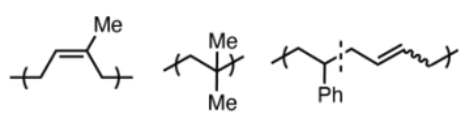

natural rubber butyl rubber styrene-butadiene

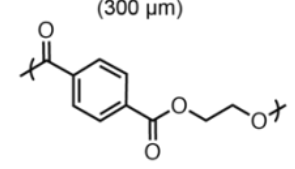

$(+2 \%$ isoprene) rubber

Figure S28. Optical microscope images of adhesive-coated glass slides that captured other microplastics: nylon (avg size $30 \mu \mathrm{m}$ ), poly(ethylene) (PE, avg size $50 \mu \mathrm{m}$ ), micronized rubber (MR, 32$99 \mu \mathrm{m}$ mesh), and poly(ethylene terephthalate) (max size $300 \mu \mathrm{m})$. 


\section{Testing MPs removal using glass slides with humic acid or surfactant present}

\section{A. Coating glass slides}

Glass slides $(1.2 \times 2.0 \mathrm{~cm})$ were prepared by drop-casting a P(2-EHA)P\&G_90k solution in THF $(10 \mu \mathrm{L}, 5 \%$ $\mathrm{w} / \mathrm{v}$ ) using a micropipette. The slides were then held for $2 \mathrm{~min}$ at room temperature and then further dried at $125^{\circ} \mathrm{C}$ in the oven for $2 \mathrm{~min}$. The slides were then cooled to room temperature for about $5 \mathrm{~min}$.

\section{B. Humic acid \& microplastic suspension}

Humic acid (HA) suspensions were prepared to have [HA] of $200 \mathrm{mg} / \mathrm{L}$ and a [PS] of $2 \mathrm{mg} / \mathrm{mL}$ by adding $\mathrm{HA}(4 \mathrm{mg})$ and $10 \mu \mathrm{m}$ PS (40mg) into $20 \mathrm{~mL}$ of $20 \%$ ethanol/water solution. This mixture was sonicated for 10 min to ensure microplastic dispersion and sufficient dissolution of HA. After sonication, the mixture was a translucent brown color.

\section{SDS \& microplastic suspension}

Sodium dodecyl sulfate (SDS) suspensions were prepared to have concentrations of $0.1 \% \mathrm{w} / \mathrm{v}$ SDS and 2 $\mathrm{mg} / \mathrm{mL} 10 \mu \mathrm{m}$ PS by adding SDS (20 mg) and PS (40 mg) into $20 \mathrm{~mL}$ of $20 \%$ ethanol/water solution. This mixture was sonicated for 10 min to ensure MP dispersion. For the glass slide experiments, $5 \mathrm{~mL}$ portions of this mixture were measured out into $20 \mathrm{~mL}$ vials in quadruplicate.

\section{Microplastics capture}

To each HA or SDS suspension, an adhesive-coated glass slide was added, and the suspensions were hand-shaken for $5 \mathrm{~min}$ at 3 shakes per second. The glass slides were then removed using tweezers and washed with $\mathrm{DI} \mathrm{H} \mathrm{H}_{2} \mathrm{O}(20 \mathrm{~mL})$ to remove unadhered MPs. The slides were air-dried for $30 \mathrm{~min}$ and analyzed using optical microscopy. Microscope images were further processed using the ImageJ 'analyze particle' function, which uses pixel contrast to identify particles and particle clusters against the background medium. Particles and particle clusters were considered based on ImageJ metrics of count and 2-dimensional surface area (SA). Percent total SA coverage of particles on the glass slides was determined by summing the SA of all individual particles and particle clusters divided over the net surface area of the image area. The HA and SDS results were compared against a control containing $2 \mathrm{mg} / \mathrm{mL}$ of $10 \mu \mathrm{m}$ PS in $20 \%$ ethanol/water.

Table S6. Summary of surface area measurements with and without humic acid present.

\begin{tabular}{|c|c|c|}
\hline run & $\begin{array}{c}\text { \% surface } \\
\text { area }\end{array}$ & average \\
\hline control run \#1 & 8.0 & \\
control run \#2 & 6.4 & $7.6 \pm 0.8 \%$ \\
control run \#3 & 8.8 & \\
control run \#4 & 7.3 & \\
\hline humic acid run \#1 & 12.1 & \\
humic acid run \#2 & 9.2 & $9 \pm 2 \%$ \\
humic acid run \#3 & 7.9 & \\
\hline
\end{tabular}


control run \#1
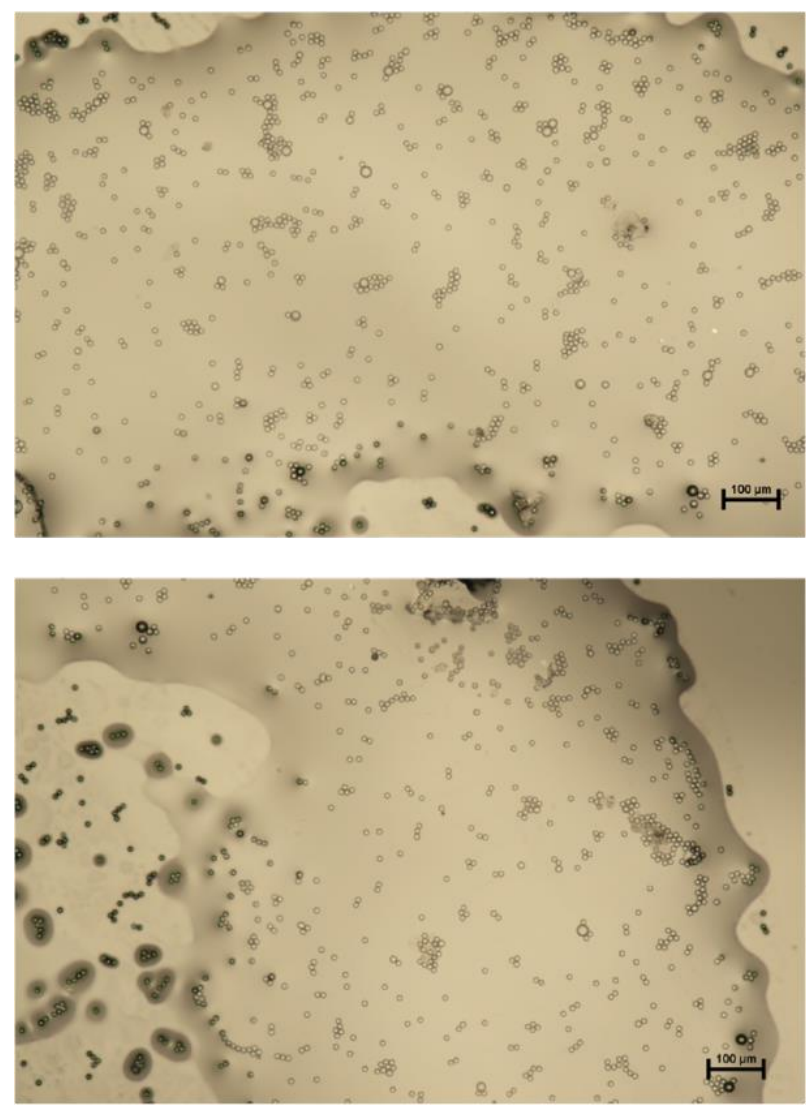

control run \#2 humic acid run \#1
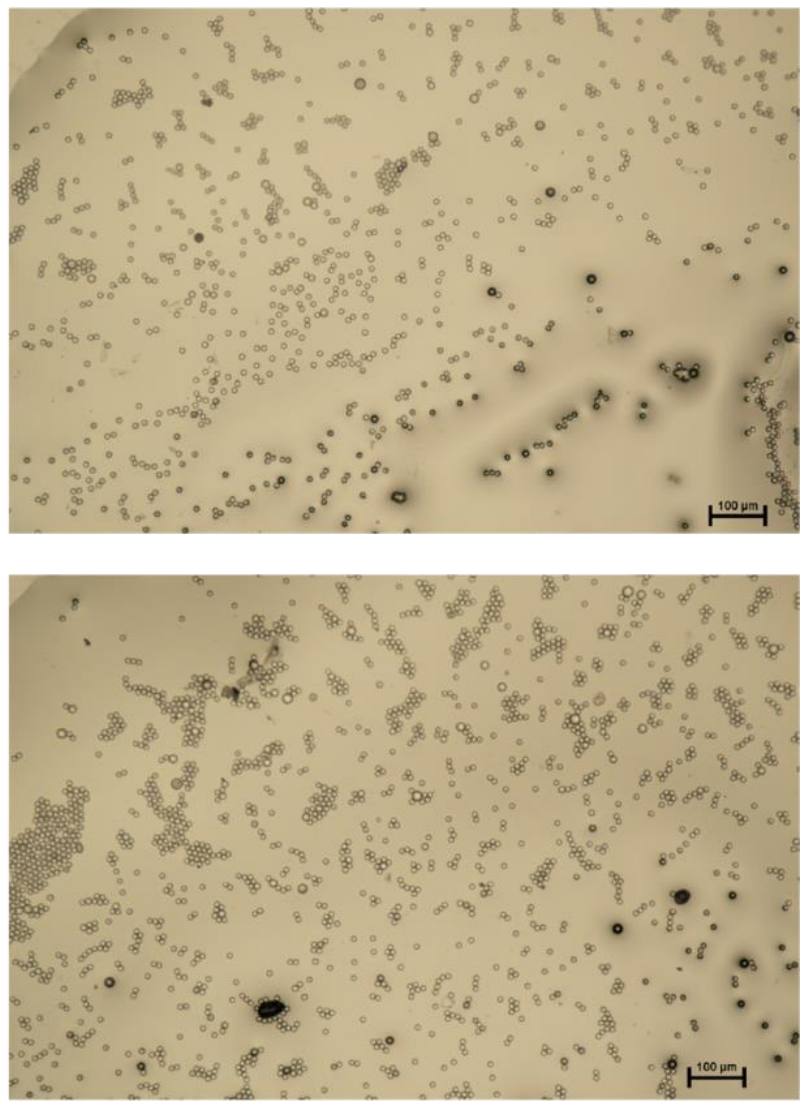

humic acid run \#2

Figure S29. Optical microscope images of adhesive-coated glass slides that captured $10 \mu \mathrm{m}$ PS microplastics with humic acid present (conc. $200 \mathrm{mg} / \mathrm{L}$ ) and without (labelled "control").

Table S7. Summary of surface area measurements with and without SDS present. (Note: The controls are the same samples as in the humic acid experiment.)

\begin{tabular}{|c|c|c|}
\hline Run & \% surface area & average \\
\hline control run \#1 & 8.0 & \multirow{3}{*}{$7.6 \pm 0.8 \%$} \\
\hline control run \#2 & 6.4 & \\
\hline control run \#3 & 8.8 & \\
\hline control run \#4 & 7.3 & \multirow{2}{*}{$44 \pm 10 \%$} \\
\hline SDS run \#1 & 44.2 & \\
\hline SDS run \#2 & $90.1^{*}$ & \\
\hline SDS run \#3 & 53.9 & \\
\hline SDS run \#4 & 34.1 & \\
\hline
\end{tabular}

${ }^{*}$ Deemed an outlier and removed when determining the average and standard deviation. 
SDS run \#1
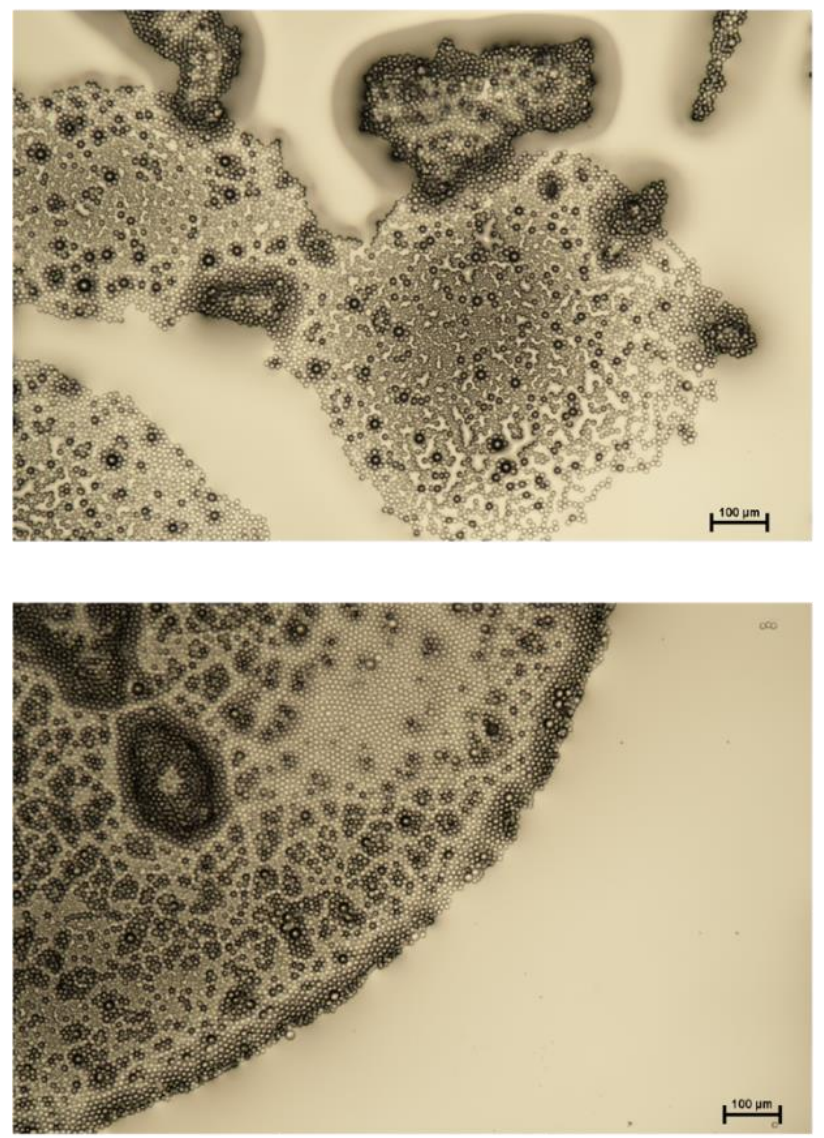

SDS run \#3
SDS run \#2
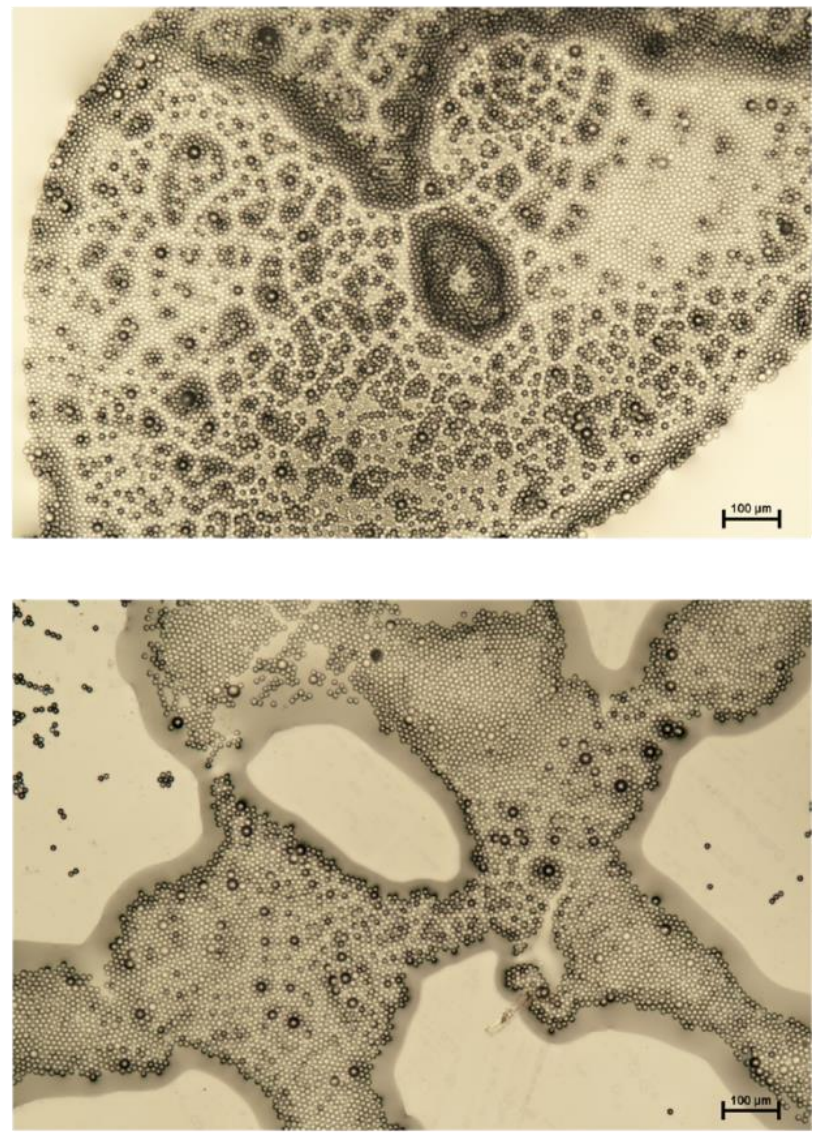

SDS run \#4

Figure S30. Optical microscope images of adhesive-coated glass slides that captured $10 \mu \mathrm{m}$ PS microplastics with SDS present (conc. $0.1 \% \mathrm{w} / \mathrm{v}$ ). 


\section{References}

1 Jo, S.; Kim, T.; Iyer, V.G.; Im, W. CHARMM-GUI: A Web-based Graphical User Interface for CHARMM. J. Comput. Chem. 2008, 29, 1859-1865.

2 Martìnez, L.; Andrade, R.; Birgin, E.G.; Martìnez, J.M. Packmol: A package for building initial configurations for molecular dynamics simulations. J. Comput. Chem. 2009, 30, 2157-2164.

3 Lee, B.; Richards, F.M. The interpretation of protein structures: estimation of static accessibility. J. Mol. Biol. 1971, 55, 379-400.

4 Dean, R.B.; Dixon, W.J. Simplified Statistics for Small Numbers of Observations. Anal. Chem. 1951, 23, 636-638. 